\title{
Exploring the link between drought indicators and impacts
}

\author{
S. Bachmair, I. Kohn, and K. Stahl \\ Hydrology, Faculty of Environment and Natural Resources, University of Freiburg, Freiburg, Germany \\ Correspondence to: S. Bachmair (sophie.bachmair@hydrology.uni-freiburg.de) \\ Received: 29 October 2014 - Published in Nat. Hazards Earth Syst. Sci. Discuss.: 15 December 2014 \\ Revised: 03 June 2015 - Accepted: 08 June 2015 - Published: 30 June 2015
}

\begin{abstract}
Current drought monitoring and early warning systems use different indicators for monitoring drought conditions and apply different indicator thresholds and rules for assigning drought intensity classes or issue warnings or alerts. Nevertheless, there is little knowledge on the meaning of different hydro-meteorologic indicators for impact occurrence on the ground. To date, there have been very few attempts to systematically characterize the indicator-impact relationship owing to sparse and patchy data on drought impacts. The newly established European Drought Impact report Inventory (EDII) offers the possibility to investigate this linkage. The aim of this study was to explore the link between hydro-meteorologic indicators and drought impacts for the case study area Germany and thus to test the potential of qualitative impact data for evaluating the performance of drought indicators. As drought indicators two climatological drought indices - the Standardized Precipitation Index (SPI) and the Standardized Precipitation Evapotranspiration Index (SPEI) - as well as streamflow and groundwater level percentiles were selected. Linkage was assessed though data visualization, extraction of indicator values concurrent with impact onset, and correlation analysis between monthly time series of indicator and impact data at the federal state level, and between spatial patterns for selected drought events. The analysis clearly revealed a significant moderate to strong correlation for some states and drought events allowing for an intercomparison of the performance of different drought indicators. Important findings were strongest correlation for intermediate accumulation periods of SPI and SPEI, a slightly better performance of SPEI versus SPI, and a similar performance of streamflow percentiles to SPI in many cases. Apart from these commonalities, the analysis also exposed differences among federal states and drought events, suggesting that the linkage is time variant and region specific to some degree. Concerning "thresholds" for drought im-
\end{abstract}

pact onset, i.e. indicator values concurrent with past impact onsets, we found that no single "best" threshold value can be identified but impacts occur within a range of indicator values. Nevertheless, the median of the threshold distributions showed differences between northern/northeastern versus southern/southwestern federal states, and among drought events. While the findings strongly depend on data and may change with a growing number of EDII entries in the future, this study clearly demonstrates the feasibility of evaluating hydro-meteorologic variables with text-based impact reports and highlights the value of impact reporting as a tool for monitoring drought conditions.

\section{Introduction}

Drought is a complex natural hazard with severe environmental and socioeconomic impacts. According to the UN Convention to Combat Drought and Desertification, drought is a "naturally occurring phenomenon that exists when precipitation has been significantly below normal recorded levels" (UN General Secretariat, 1994). Although little can be done to prevent this naturally occurring hazard, actions can be taken to reduce the societal vulnerability to drought. Such actions include the development of drought monitoring and early warning (M \& EW) systems and drought plans to enhance drought preparedness (e.g., Wilhite et al., 2000; Wilhite and Knutson, 2008; Wilhite and Svoboda, 2000). Drought M \& EW systems are based on different drought indicators or indices, which are variables describing drought conditions derived from predominantly meteorological or hydrological data. Knowledge on drought conditions expressed through an indicator, however, does not directly translate into understanding when and where drought impacts will occur given the complexity of how a prolonged 
precipitation deficit propagates though the hydrological cycle and interacts with environmental and socioeconomic factors. Nevertheless, information on the occurrence, timing, and severity of a drought impact is usually what matters most to stakeholders. Therefore there is a vital need for research on the link between commonly used drought indicators and impacts (e.g., Kallis, 2008; Stagge et al., 2015a; Stahl et al., 2012).

Especially for the development of drought plans knowledge on the relationship between drought indicators and impacts is important to infer meaningful threshold values triggering a management response (Steinemann and Cavalcanti, 2006; Steinemann, 2003, 2014). A recent survey among state drought managers in the US revealed that drought indicators and derived trigger values are often used without clarity about the relevance or effectiveness of this indicator (Steinemann, 2014). One reason for little consensus on the appropriateness of different indicators for drought $\mathrm{M} \& \mathrm{EW}$ is sparse and patchy data for "ground truthing" drought indicators, i.e. evaluating drought indicators with impact information. Since drought is a slow-onset "creeping" hazard (Gillette, 1950) with multifaceted impacts on different domains and sectors it is less visible than, for instance, earthquakes or floods. Apart from some exceptions (e.g., agricultural yield statistics) it is challenging to find information on the variety of drought impacts, which are mainly non-structural (not associated with physical damages to buildings, infrastructure, and other assets) and difficult to quantify in monetary terms (Logar and van den Bergh, 2013). To address these shortcomings, an online database for collecting user-based reports on drought impacts was launched in the United States some years ago (US Drought Impact Reporter (DIR); Wilhite et al., 2007). For Europe, a similar system has been recently established, however as a research database with a focus on past drought events, rather than as a real-time monitoring tool. This European Drought Impact report Inventory (EDII), which was broadly modeled after the US Drought Impact Reporter, compiles text-based reports on drought impacts from a variety of sources (Stahl et al., 2012; Stahl et al., 2015). Inventories like the DIR or the EDII offer the possibility to evaluate drought indicators with information on impact occurrence.

A large body of literature exists on the vast amount of drought indicators (for recent reviews see Heim Jr., 2002; Keyantash and Dracup, 2002; Zargar et al., 2011) and many studies have assessed the linkage between different hydrometeorologic indicators (e.g., Anderson et al., 2011; Hao and AghaKouchak, 2014; Haslinger et al., 2014; Keyantash and Dracup, 2002; Steinemann, 2003; Vicente-Serrano et al., 2012). While fewer studies explored the relationship between drought indicators and a quantitative impact variable, such as agricultural yield or a vegetation response proxy (e.g., Ceglar et al., 2012; Mavromatis, 2007; Potop, 2011; Quiring and Ganesh, 2010; Quiring and Papakryiakou, 2003; Rossi and Niemeyer, 2010; Sepulcre-Canto et al., 2012;
Vicente-Serrano et al., 2012), only three studies have exploited text-based reports of drought impacts for evaluating the meaning of drought indicators or the statistical modeling of the likelihood of impact occurrence (Dieker et al., 2010; Blauhut et al., 2015; Stagge et al., 2015a). The value of incorporating impact information into drought M\&EW lies in moving from a hazard-based, reactive to a risk-based, proactive approach of drought management, as often postulated (Wilhite et al., 2000). Drought indicators only characterize the hazard, leaving room for interpretation whether and when this will trigger impacts. Depending on the vulnerability of a system a given hazard intensity will or will not evoke adverse environmental, economic or social effects. Vulnerability assessment is a common tool for closing the gap between hazard information and knowledge of risk of a certain region or exposed entity (e.g., Birkmann et al., 2013; Kallis, 2008; Knutson et al., 1998); its outcome, however, will strongly depend on the quality of available indicator data and assumptions made (Naumann et al., 2014). Directly evaluating drought indicators with impact occurrence allows, in theory, gaining insight into the cause-effect relationship of a physical water deficit without any assumptions on vulnerability. Nevertheless, there are numerous challenges and potential sources of bias during the collection of drought impact information (Lackstrom et al., 2013); text-based impact reports thus only represent a proxy for impact occurrence.

Given the limited knowledge on the potential of qualitative impact data for evaluating the meaning of drought indicators, this study aims at exploring the link between hydrometeorologic drought indicators and text-based information of drought impacts. To test the feasibility of linking indicators with impacts, Germany was chosen as a case study given its good coverage in the EDII and availability of hydrometeorologic data. Specifically, we ask the following research questions:

- Is there a discernible link between drought impact occurrence derived from text-based information and different hydro-meteorologic indicators commonly applied for operational drought monitoring and early warning (M\& EW) systems?

- If there is a link, which indicator or set of indicators best explain drought impact occurrence for the case study area Germany?

- Can impact occurrence be attributed to a specific indicator threshold?

\section{Methods}

\subsection{Drought indicator data}

Four indicators were selected representing drought propagation in different domains of the hydrological cycle: the 

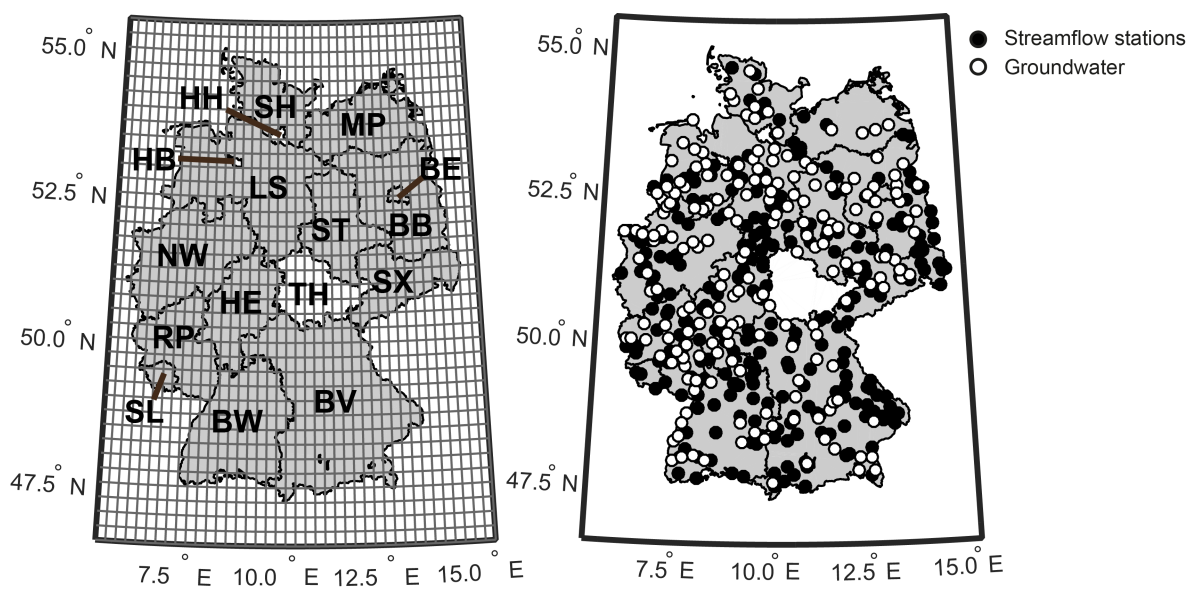

Figure 1. Overview on study area and data. Left panel: federal states of Germany overlain by raster displaying SPI or SPEI resolution $\left(0.25^{\circ}\right)$. Right panel: distribution of streamflow and groundwater monitoring stations. The states $\mathrm{HB}, \mathrm{HH}$, and $\mathrm{TH}$ (displayed in white) are not considered in the analysis due to very few impact data.

Standardized Precipitation Index (SPI) (McKee et al., 1993), the Standardized Precipitation Evaporation Index (SPEI) (Vicente-Serrano et al., 2010), and two hydrological indicators, namely streamflow percentiles $(Q)$, and percentiles of groundwater levels $(G)$. SPI-n and SPEI-n are statistical indicators that compare the total precipitation or climatic water balance at a particular location during a period of $n$ months with its multiyear average (Vicente-Serrano et al., 2010; Zargar et al., 2011). As aggregation periods of SPI and SPEI we selected 1-8, 12, and 24 months. SPI and SPEI monthly time series are based on E-OBS gridded data (version 9.0; $0.25^{\circ}$ regular spatial grid; Haylock et al., 2008) and were calculated using the R Package "SCI" (Gudmundsson et al., 2014; Stagge et al., 2015b). Standardization is based on the gamma distribution for SPI and the generalized logistic distribution for SPEI (reference period: 1971-2010); potential evapotranspiration for SPEI is estimated using Hargreaves method (Hargreaves, 1994). As spatial units of drought indicator aggregation, the 16 federal states (corresponding to European Union NUTS 1 regions) were chosen - Baden-Wuerttemberg (BW), Bavaria (BV), Berlin (BE), Brandenburg (BB), Hanseatic City of Bremen (HB), Hanseatic City of Hamburg (HH), Hesse (HE), Mecklenburg-Western Pomerania (MP), Lower Saxony (LS), North Rhine-Westphalia (NW), RhinelandPalatinate (RP), Saarland (SL), Saxony (SX), SaxonyAnhalt (ST), Schleswig-Holstein (SH), and Thuringia (TH). Three of the 16 states were not considered in the analysis due to very few impact data (HB, HH, and TH; see Sect. 2.2 for exclusion criteria). Figure 1 shows the SPI or SPEI grid cell coverage per federal state. For the spatial aggregation of SPI or SPEI the following metrics were calculated per federal state: mean ( $\overline{\mathrm{SPI}}$ and $\overline{\mathrm{SPEI}})$, 10th percentile ( $\mathrm{SPI}_{10}$ and SPEI $\left._{10}\right)$, and the percent area in drought ( $A_{\text {SPI }}$ and $\left.A_{\text {SPEI }}\right)$, which is defined as percent area with SPI or SPEI $<-1$.
Monthly streamflow percentiles are based on daily records of streamflow for several gauging stations per federal state. Time series of monthly groundwater percentiles originate from weekly to monthly readings of groundwater levels or spring discharge for several monitoring stations per state. Figure 1 displays the spatial distribution of stations (amount of streamflow and groundwater gauging stations per federal state, respectively: 28/15 (BW), 69/26 (BV), 21/18 (BB), 19/18 (HE), 38/42 (LS), 7/4 (MP), 23/18 (NW), 20/18 (RP), 9/9 (SH), 3/0 (SL), 23/10 (SX), 16/14 (ST), no data (BE). Many of these stations are used for the federal states' hydrological forecasting systems and thus represent stations with good data quality. Note that streamflow gauging stations represent a variety of catchments varying in size and catchment characteristics, many of them being anthropogenically influenced. For more details on the selection of gauging stations per state see Kohn et al. (2014). The reference period for the calculation of monthly streamflow and groundwater level percentiles is 1970-2011. Similar to the spatial aggregation of SPI or SPEI, different indicators metrics for streamflow or groundwater level percentiles were calculated per federal state: mean $(\bar{Q}$ and $\bar{G})$, 10th percentile $\left(Q_{10}\right.$ and $\left.G_{10}\right)$, and percent stations under low flow conditions (percentile $<0.3$; $A_{Q}$ and $\left.A_{\mathrm{G}}\right)$.

\subsection{Drought impact data}

Information on drought impacts originates from the European Drought Impact report Inventory (EDII) (Stahl et al., 2012). According to the EDII a "drought impact" is a negative environmental, economic or social effect experienced under drought conditions. Consequently, precipitation shortfalls, anomalously low levels of soil moisture, water levels or streamflow without negative consequences (for water uses, ecosystems, agricultural yields etc.) or at least se- 
rious concerns, are not regarded as drought impacts. EDII entries are based on text-based impact reports. These reports come from a variety of sources such as governmental or NGO reports, books, newspapers/digital media or journal articles. Each drought impact report in the inventory contains (1) a spatial reference (different levels of geographical regions including the European Union NUTS (Nomenclature of Territorial Units for Statistics) regions standard), (2) a temporal reference (at least the year of occurrence), and (3) an assigned impact category (there are 15 impact categories with further division into impact subtypes): agriculture and livestock farming, forestry, freshwater aquaculture and fisheries, energy and industry, waterborne transportation, tourism and recreation, public water supply, water quality, freshwater ecosystems, terrestrial ecosystems, soil system, wildfires, air quality, human health and public safety, and conflicts). More information on each drought impact report is available in the inventory but is not used for the analysis. Examples of drought impacts are crop losses, reduced production of thermal and nuclear power plants, impaired navigability of streams, local water supply shortage, or increased mortality of aquatic species, to name a few. Stahl et al. (2012) provide further information on the EDII and all impact entries can be searched and viewed online at http://www.geo.uio.no/edc/droughtdb/.

About $30 \%$ of the EDII entries represent impacts that occurred in Germany (761 impact reports as of the contents of August 2014). For the statistical analysis the qualitative information on drought impacts was converted into monthly time series of number of drought impact occurrences per state. The following decisions were made during the conversion of "drought impact reports" (EDII entries) into "drought impact occurrences" (hereafter termed $I$ ).

- Spatial reference: an impact report often contains information on drought impacts that occurred at several locations and/or impacts representing different impact subtypes. An impact report was converted into several $I$ if (1) the impact report states impact occurrence in several federal states or (2) an impact falls into several impact subtypes. Note that an $I$ assigned to a specific state may both represent an impact affecting the entire state (e.g., impact report states reduction of crop yield for the entire state) or an impact occurring at a smaller unit within that state (e.g., impact occurred in city $X$ of state $A$ ). Both types of spatial reference have equal weight in the analysis (one $I$ ). Impact reports with country-level information without indication of affected states were not considered in the analysis.

- Temporal reference: impact reports indicating a month for start and end of drought impact occurrence were converted accordingly. If only the season was provided, drought impacts were assumed to have occurred during each month of that season (winter $=$ DJF, spring $=$ MAM, summer $=$ JJA, fall $=$ SON). Impact re- ports with only the year of occurrence stated were omitted from the analysis. Note that in the analysis we distinguish between months with $I$ (months during which drought impacts occurred), and months with $I$ onset (months where one or several drought impacts started to occur).

For the analysis, the time period 1970-2011 was chosen. Out of all impact reports for Germany, 685 fell into the time period $1970-2011 ; 38 \%$ of these entries had either countrylevel information only or no month/season indicated and was thus discarded. The conversion of the remaining impact reports resulted in 1569 drought impact occurrences with spatial and temporal reference (state-level and month). In addition to the number of $I$ of all impact categories we also considered the number of drought impact occurrences associated with hydrological drought (hereafter termed $I_{\mathrm{h}}$ ), i.e. all impacts resulting from drought conditions of surface waters or groundwater. The differentiation between $I$ and $I_{\mathrm{h}}$ is based on a keyword search of the impact description field in the database and thus does not strictly follow any impact category or impact subtype. Examples are impaired navigability of streams, increased temperature in surface waters above legal limit for effluent discharge, drying up of reservoirs, water supply shortages/problems, or reduced fishery production. Impacts excluded from $I_{\mathrm{h}}$ are, e.g., agricultural and forestry impacts, impacts due to heatwaves, soil subsidence, or fire. The temporal, spatial, and categorical distribution of $I$ is displayed in Fig. 2. Additionally, Table 1 shows the number of $I$ and $I_{\mathrm{h}}, I$ and $I_{\mathrm{h}}$ onsets, and months with $I$ and $I_{\mathrm{h}}$ per federal state. Due to very few impact data for the states HB, HH, and TH these states are omitted from analysis (threshold for exclusion: $<10$ months with $I$ ).

\subsection{Data analysis}

The linkage between drought indicators and impacts was assessed through data visualization, correlation analysis, and extraction of indicator values concurrent with impact onset. Two approaches were followed: (1) linkage between time series of indicator-impact data per state to gain insight into the spatial variability of the indicator-impact relationship, and (2) linkage between spatial patterns of indicator-impact data for selected drought events.

\subsubsection{Linkage between time series of indicator-impact data per state}

For this approach only years with at least one $I$ within Germany were considered, which resulted in 17 years. The rationale behind this is to exclude years where drought conditions may have occurred but no impact reports are available given the undoubtedly biased temporal coverage of EDII entries. Since the search for impact reports in Germany focused on known drought events, the absence of impact reports in the EDII for years with drought conditions comes 
Table 1. Number of drought impact occurrences and onsets per federal state.

\begin{tabular}{lccccccccccccc}
\hline & SH & MP & LS & ST & BB & BE & NW & HE & SX & RP & SL & BW & BV \\
\hline$n I$ & 34 & 54 & 107 & 46 & 114 & 57 & 143 & 95 & 50 & 182 & 42 & 228 & 382 \\
$n I_{\text {h }}$ & 15 & 19 & 49 & 6 & 67 & 39 & 111 & 56 & 21 & 117 & 29 & 170 & 306 \\
Months with $I$ & 15 & 27 & 37 & 22 & 29 & 17 & 29 & 26 & 30 & 30 & 11 & 33 & 24 \\
Months with $I_{\mathrm{h}}$ & 7 & 12 & 20 & 6 & 12 & 4 & 24 & 17 & 13 & 24 & 5 & 30 & 19 \\
$n I$ onset & 19 & 19 & 46 & 18 & 47 & 21 & 70 & 46 & 17 & 95 & 17 & 116 & 159 \\
$n I_{\mathrm{h} \text { onset }}$ & 12 & 3 & 22 & 3 & 26 & 13 & 55 & 31 & 7 & 69 & 12 & 93 & 124 \\
\hline
\end{tabular}

$n I=$ number of drought impact occurrences; $n I_{\mathrm{h}}=$ number of hydrological drought impact occurrences; $n I$ onset $=$ number of drought impact onsets; $n I_{\mathrm{h}}$ onset $=$ number of hydrological drought impact onsets.

a)

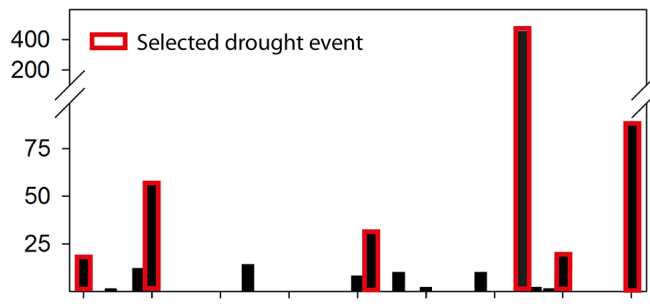

197119761981198619911996200120062011

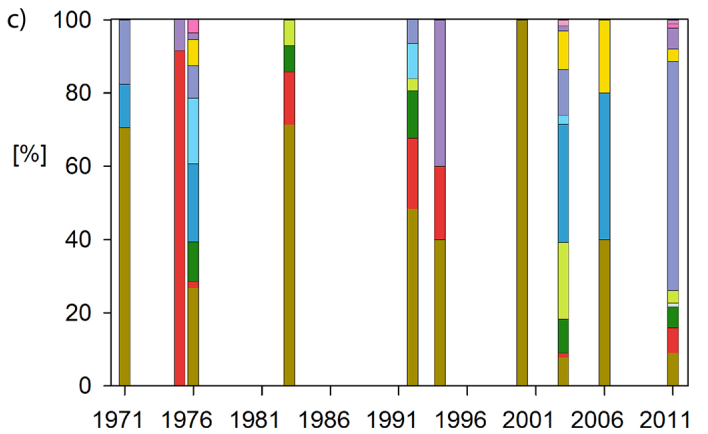

b)
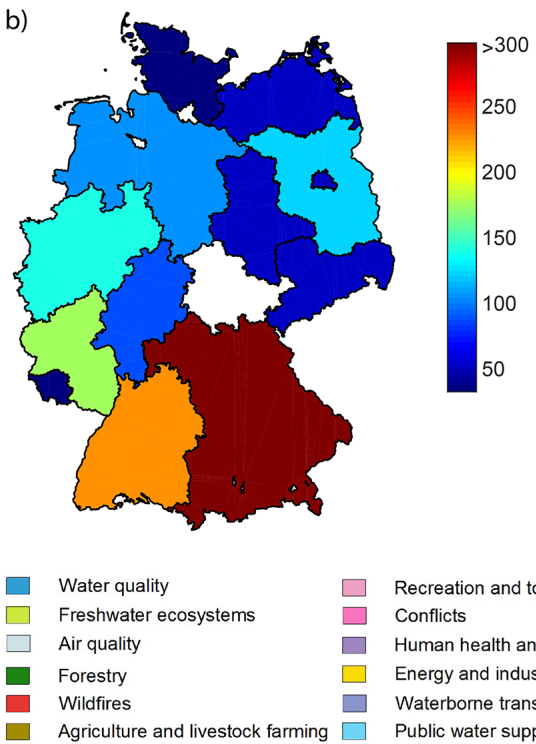

Recreation and tourism Conflicts Human health and public safety Energy and industry Waterborne transportation Public water supply

Figure 2. (a) Number of drought impact onsets in Germany per year. The bars outlined in red represent the drought events selected for analysis. (b) Spatial distribution of number of drought impact occurrences. The states HB, HH, and TH (displayed in white) are not considered in the analysis due to very few impact data. (c) Distribution of impacts by impact category.

from a lack of publishing or finding drought impact reports rather than an absence of impact occurrences. To account for this we decided on the above described censoring approach. Note that all months of the respective years were considered ( $n=204$ months).

To determine the relationship between drought indicators and impacts we computed Spearman rank correlation coefficients and corresponding significance levels for

- time series of $\overline{\text { SPI }}$ or $\overline{\text { SPEI }}$ or $\bar{Q}$ or $\bar{G}$ vs. time series of $I$ or $I_{\mathrm{h}}$ per federal state;

- time series of $\mathrm{SPI}_{10}$ or $\mathrm{SPEI}_{10}$ or $Q_{10}$ or $G_{10}$ vs. time series of $I$ or $I_{\mathrm{h}}$ per federal state;

- and time series of $A_{\mathrm{SPI}}$ or $A_{\mathrm{SPEI}}$ or $A_{Q}$ or $A_{\mathrm{G}}$ vs. time series of $I$ or $I_{\mathrm{h}}$ per federal state. Note that for SPI or SPEI the aggregation periods $1-8,12$, and 24 months were considered.
The cross-correlation analysis was only carried out for impact time series with at least 10 months with impact occurrence (see Table 1 for months with $I$ and $I_{\mathrm{h}}$ per federal state). Analyzing the indicator and impact time series for temporal autocorrelation revealed that time series of SPI and SPEI of longer accumulation periods, and streamflow and groundwater level percentiles show autocorrelation to a certain degree. Temporal autocorrelation of time series in cross-correlation analysis violates the assumption of serial independence and increases the likelihood of Type I error (Hurlbert, 1984; Jenkins, 2005). To account for temporal autocorrelation in the cross-correlation analysis we adjusted the degrees of freedom during the calculation of significance levels according to the method by Pyper and Peterman (1998). While we use rank correlation for the cross-correlation analysis, autocorrelation was assessed using Pearson correlation. The impact data were square-root transformed for the autocorrelation analysis. We define strength of correlation as follows: 
Table 2. Information on selected drought events: duration and number of drought impact occurrences and onsets.

\begin{tabular}{lcccccc}
\hline $\begin{array}{l}\text { Drought } \\
\text { event }\end{array}$ & Jun-Dec 1971 & Feb-Aug 1976 & Mar-Aug 1992 & $\begin{array}{c}\text { Feb 2003- } \\
\text { Feb 2004 }\end{array}$ & Jun-Aug 2006 & Jan-Dec 2011 \\
\hline Duration (months)* & 7 & 7 & 6 & 13 & 3 & 12 \\
$n I$ & 48 & 146 & 72 & 931 & 33 & 155 \\
$n I_{\mathrm{h}}$ & 18 & 82 & 18 & 736 & 422 & 111 \\
$n I$ onset & 15 & 55 & 30 & 340 & 12 & 88 \\
$n I_{\mathrm{h}}$ onset & 5 & 33 & 6 & 63 \\
\hline
\end{tabular}

* Event delineation based on impact occurrence (see Sect. 2.3). $n I=$ number of drought impact occurrences; $n I_{\mathrm{h}}=$ number of hydrological drought impact occurrences; $n I$ onset $=$ number of drought impact onsets; $n I_{\mathrm{h}}$ onset $=$ number of hydrological drought impact onsets.

$0-0.1$ (no correlation), $>0.1-0.3$ (weak), $>0.3-0.6$ (moderate), $>0.6-0.9$ (strong), and $>0.9$ (very strong).

Moreover, indicator values associated with drought impact onset were extracted from each drought indicator time series per federal state. Since indicator values concurrent with past impact onset may represent thresholds for impact occurrence, we hereafter use the term indicator "threshold" when referring to the former. If $x I$ onsets occurred in 1 month the respective indicator value is represented $x$ times in the threshold distribution. Indicator threshold distributions were visualized as box plots and analyzed for their median values if number of $I$ or $I_{\mathrm{h}}$ onset $>=5 ; n>=5$ complied with the box plot visualization guidelines by Krzywinski and Altman (2014). Note that SPI and SPEI threshold distributions are based on $I$ onset, while $Q$ and $G$ distributions are based on $I_{\mathrm{h}}$ onset.

\subsubsection{Linkage between spatial patterns of indicator-impact data}

For this approach the link between spatial patterns of indicator-impact data across the federal states was investigated for selected drought events. A drought event is defined as a time period of drought impact occurrence after a time with no impacts; we set a threshold of 35 I per event affecting more than one-third of the selected states to be considered in the analysis. This resulted in six selected events: 1971, 1976, 1992, 2003, 2006, and 2011. The reason for defining events via impact occurrence over exceedance of an indicator threshold is to focus on events with good coverage of impact data. Event duration is set to the time period of consecutive impact occurrence from first to last occurrence, which may be intermitted by 1 month with no impact. See Table 2 for duration and timing of drought events and number of $I$ or $I_{\mathrm{h}}$ and $I$ or $I_{\mathrm{h}}$ onsets. For each event, drought indicator time series were aggregated over the duration of the event, resulting in different indicator metrics per federal state and event: mean of $\overline{\mathrm{SPI}}$ or $\overline{\mathrm{SPEI}}$ or $\bar{Q}$ or $\bar{G}$, minimum of $\mathrm{SPI}_{10}$ or $\mathrm{SPEI}_{10}$ or $Q_{10}$ or $G_{10}$, and maximum of $A_{\mathrm{SPI}}$ or $A_{\mathrm{SPEI}}$ or $A_{Q}$ or $A_{\mathrm{G}}$. Spearman rank correlation coefficients and corresponding significance levels were computed between spatial patterns of
- mean $\overline{\mathrm{SPI}}$ or $\overline{\mathrm{SPEI}}$, minimum $\mathrm{SPI}_{10}$ or $\mathrm{SPEI}_{10}$, maximum $A_{\mathrm{SPI}}$ or $A_{\mathrm{SPEI}}$ vs. number of $I$ or $I_{\mathrm{h}}$ per event ( $n=13$; all states except the excluded states $\mathrm{HB}, \mathrm{HH}$, and $\mathrm{TH})$;

- mean $\bar{Q}$, minimum $Q_{10}$, maximum $A_{Q}$ vs. number of $I$ or $I_{\mathrm{h}}$ per event $(n=12$; as above, yet no streamflow data for $\mathrm{BE})$;

- and mean $\bar{G}$, minimum $G_{10}$, maximum $A_{\mathrm{G}}$ vs. number of $I$ or $I_{\mathrm{h}}$ per event ( $n=11$; as above, yet no groundwater data for BE and SL).

Correlation for $I$ or $I_{\mathrm{h}}$ was only assessed if more than onethird of the selected states were affected. Additionally, indicator values associated with drought impact onset during each event were extracted from the drought indicator time series. Indicator values of months with $x I$ onsets are represented $x$ times in the threshold distribution. Contrary to the linkage-between-time-series approach per federal state, indicator values of all affected states go into the threshold distribution per drought event. As for the linkage-betweentime-series approach, the resulting indicator threshold distributions per event were visualized as box plots and analyzed for their median values if number of $I$ or $I_{\mathrm{h}}$ onsets $>=5$ ).

\section{Results}

\subsection{Linkage between time series of indicator-impact data}

Figure 3 displays correlation coefficients between time series of drought indicators and $I$ or $I_{\mathrm{h}}$ per federal state, which range from -0.46 to 0.47 . The indicator metrics mean, 10th percentile, and percent area in drought show differing directions of $r$. While the mean and 10th percentile are generally negatively correlated with $I$ (lower indicator values coinciding with higher number of $I$ ), the percent area in drought is mainly positively correlated (larger area associated with higher number of $I$ ). However, there are some instances with a non-significant inverse direction of $r$ (nonmeaningful direction). The weak-to-moderate strength of correlation for several federal states clearly reveals a link 

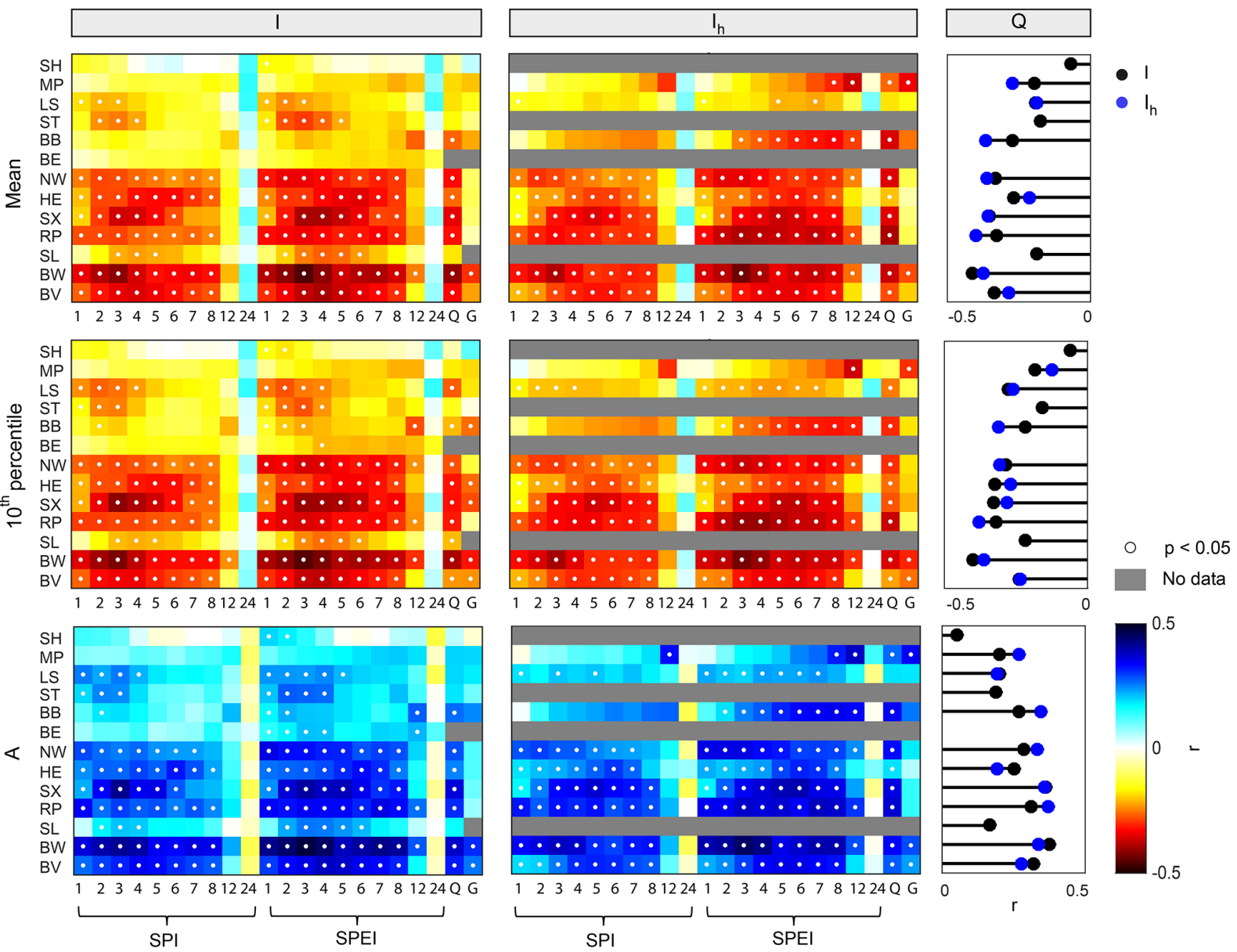

No data

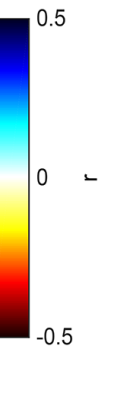

Figure 3. Rank correlation coefficients $(r)$ between time series of drought indicators (SPI or SPEI or streamflow $(Q)$ or groundwater level $(G)$ percentiles) and drought impact occurrences ( $I$ or $I_{\mathrm{h}}$ ) per federal state sorted by approximate geographical location (northwest to southeast). Mean, 10th percentile, and $A$ (percent area in drought) represent different indicator metrics. The right panel highlights the difference in $r$ between $I$ and $I_{\mathrm{h}}$ for streamflow percentiles.

between drought indicators and text-based information on drought impacts. Most moderate correlations are statistically significant $(p<0.05)$, as indicated by the white dots in Fig. 3. Figure 3 also reveals strong differences among states. While the states BW, BV, NW, RP and SX show a moderate correlation for several drought indicators, the states BE, BB, MP, LS, SL, and ST display predominantly weak correlations. SH shows no correlation for most indicators.

When focusing on commonalities in correlation patterns for $I$, the following findings become apparent: SPEI in most cases shows a slightly higher $r$ than the corresponding SPI. The $r$ for streamflow percentiles is for some states comparable to SPI, yet often shows lower values. Groundwater level percentiles show only a weak correlation with time series of drought impact occurrence. Regarding the accumulation period of SPI and SPEI the strongest correlation is found for intermediate accumulation periods. For half of the states the highest $r$ is associated with a precipitation or water balance anomaly of 3 or 4 months. Notable is an inverse direction of $r$ for SPI-24 and SPEI-24 for most federal states, yet the correlation is not statistically significant. The differences between indicator metrics (mean versus 10th percentile versus percent area in drought) are negligible (see vertical series of plots in Fig. 3). The picture for correlation with $I_{\mathrm{h}}$ is similar, yet some indicators display a higher $r$ than with $I$, especially in states with generally weak correlations (BB and MP). Also, there is a shift towards stronger correlation with longer accumulation periods of SPI and SPEI for $I_{\mathrm{h}}$ over $I$. The right panel of Fig. 3 highlights the difference in $r$ between $I$ and $I_{\mathrm{h}}$ for streamflow percentiles. As can be seen, there is no consistent picture of higher $r$ between time series of $Q$ and $I_{\mathrm{h}}$ than between $Q$ and $I$.

In terms of thresholds for $I$ or $I_{\mathrm{h}}$ onset it becomes evident that no single threshold value exists triggering the onset of drought impacts. The box plots in Fig. 4 show that the interquartile range (IQR) of the $\overline{\text { SPI }}$ or $\overline{\text { SPEI }}$ distributions spans an absolute value of ca. 0.3 to 1 for most states. Apart from this, the box plots and median of the $\overline{\mathrm{SPI}}$ or $\overline{\mathrm{SPEI}}$ and $\mathrm{SPI}_{10}$ 

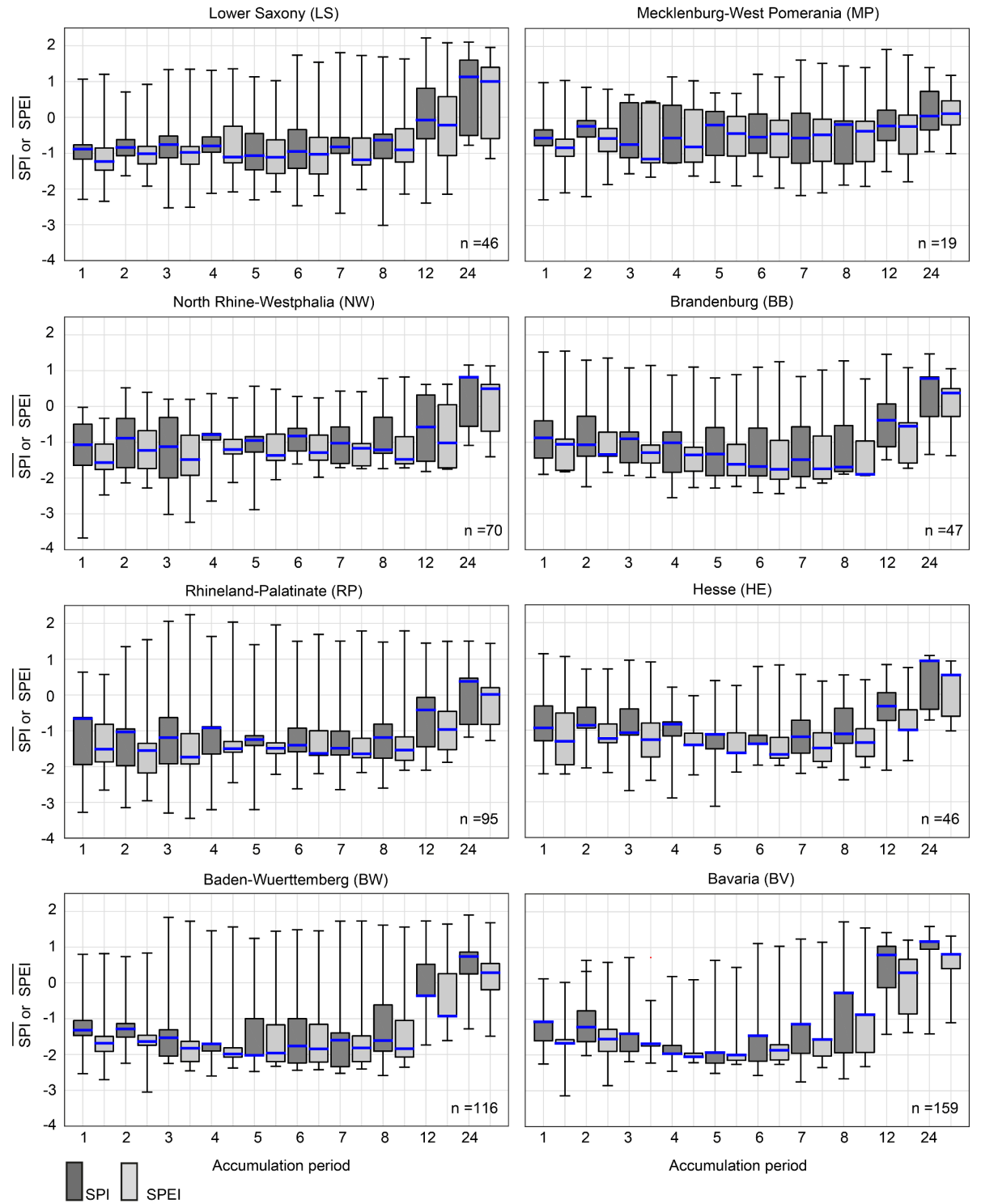

Figure 4. Distribution of $\overline{\text { SPI }}$ or SPEI concurrent with $I$ onset in eight selected federal states; $n=$ number of $I$ onsets. The blue line inside each box plot represents the median; the whiskers of the box plots extend to the minimum and maximum of the distribution.

or $\mathrm{SPEI}_{10}$ distributions reveal interesting differences among states and SPI or SPEI accumulation periods ( $\overline{\text { SPI }}$ or $\overline{\text { SPEI }}$ displayed in Fig. 4 and Table 3; $\mathrm{SPI}_{10}$ or $\mathrm{SPEI}_{10}$ not shown).

1. Differences among states - when neglecting the variability and complexity of the pattern within each state, there appears a pattern of some states showing more negative threshold values than others. In the states RP,

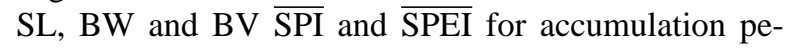
riods $1-8$ tend to be more negative (IQR predominantly between -1 and -2 ) than in the states $\mathrm{SH}$, MP, LS, and ST, where the IQR primarily lies between 0 and -1 . If only considering the indicator showing the highest correlation with drought impact occurrence, a threshold (median of $\overline{\text { SPI }}$ or $\overline{\text { SPEI distribution) }}$ of -1.7 (RP), -1.9 (SL), -1.8 (BW), and $-2(\mathrm{BV})$ for the first group, and $-1.3(\mathrm{SH}),-0.5(\mathrm{MP}),-1$ (LS), and -1.4 (ST) for the second group of states can be identified (see Table 3 for median values of all indicator distributions). The former states are located in the south/southwest of Germany, whereas the latter are situated in the north/northeast. The indicator thresholds of the more central states NW, HE, and SX lie somewhat in the middle of this, show more variability and cannot be clearly assigned to one group or the other. The northeastern states BB and BE show similar thresholds as in SH, MP, LS, and ST for shorter accumulation periods of $\overline{\text { SPI }}$ and SPEI (1-4 months); however, for intermediate and long accumulation periods the thresholds are 
Table 3. Median of indicator distribution ( $\overline{\mathrm{SPI}}$ or $\overline{\mathrm{SPEI}}$ or $\bar{Q}$ or $\bar{G}$ ) concurrent with drought impact onset per federal state. The bold values represent the indicator with highest absolute value of $r$ between time series of drought indicators and $I$ per federal state.

\begin{tabular}{|c|c|c|c|c|c|c|c|c|c|c|c|c|c|c|}
\hline & Acc. & $\mathrm{SH}$ & MP & LS & ST & BB & $\mathrm{BE}$ & NW & $\mathrm{HE}$ & SX & $\mathrm{RP}$ & SL & BW & BV \\
\hline$\overline{\text { SPI }}$ & 1 & -1.23 & -0.56 & -0.89 & -0.58 & -0.88 & -0.31 & -1.07 & -0.94 & -1.08 & -0.66 & -1.22 & -1.32 & -1.07 \\
\hline$\overline{\text { SPEI }}$ & 1 & -1.34 & -0.83 & -1.23 & -1.06 & -1.05 & -0.92 & -1.57 & -1.31 & -1.26 & -1.51 & -1.52 & -1.69 & -1.68 \\
\hline$\overline{\text { SPI }}$ & 2 & -1.03 & -0.23 & -0.84 & -1.14 & -1.07 & -0.90 & -0.88 & -0.87 & -1.11 & -1.03 & -1.81 & -1.28 & -1.22 \\
\hline$\overline{\text { SPEI }}$ & 2 & -1.26 & -0.57 & -1.01 & -1.32 & -1.34 & -1.28 & -1.23 & -1.23 & -1.40 & -1.55 & -1.63 & -1.64 & -1.56 \\
\hline$\overline{\text { SPI }}$ & 3 & -1.13 & -0.74 & -0.76 & -1.01 & -0.91 & -1.23 & -1.12 & -1.07 & -1.70 & -1.19 & -1.45 & -1.53 & -1.41 \\
\hline$\overline{\text { SPEI }}$ & 3 & -1.21 & -1.15 & -0.98 & -1.37 & -1.29 & -1.46 & -1.48 & -1.27 & -1.81 & -1.74 & -1.91 & -1.82 & -1.68 \\
\hline$\overline{\text { SPI }}$ & 4 & -0.42 & -0.56 & -0.80 & -0.64 & -1.01 & -1.68 & -0.78 & -0.83 & -1.05 & -0.92 & -2.00 & -1.70 & -1.96 \\
\hline$\overline{\text { SPEI }}$ & 4 & -0.77 & -0.81 & -1.11 & -0.87 & -1.35 & -1.78 & -1.20 & -1.41 & -1.37 & -1.50 & -1.94 & -1.99 & -2.05 \\
\hline SPI & 5 & -0.49 & -0.19 & -1.07 & -0.50 & -1.33 & -2.15 & -0.95 & -1.12 & -0.84 & -1.25 & -2.20 & -2.02 & -1.93 \\
\hline$\overline{\text { SPEI }}$ & 5 & -0.79 & -0.44 & -1.11 & -0.79 & -1.62 & -1.87 & -1.37 & -1.63 & -1.18 & -1.49 & -1.84 & -1.96 & -2.00 \\
\hline$\overline{\text { SPI }}$ & 6 & -0.64 & -0.53 & -0.95 & -0.40 & -1.68 & -1.65 & -0.83 & -1.38 & -0.67 & -1.40 & -1.86 & -1.76 & -1.46 \\
\hline$\overline{\text { SPEI }}$ & 6 & -1.00 & -0.44 & -1.03 & -0.55 & -1.76 & -1.94 & -1.29 & -1.68 & -0.85 & -1.63 & -1.87 & -1.84 & -1.87 \\
\hline$\overline{\text { SPI }}$ & 7 & -1.00 & -0.56 & -0.82 & -0.62 & -1.49 & -2.14 & -1.03 & -1.19 & -0.40 & -1.49 & -1.79 & -1.60 & -1.14 \\
\hline$\overline{\text { SPEI }}$ & 7 & -1.23 & -0.47 & -1.18 & -0.80 & -1.74 & -2.11 & -1.17 & -1.50 & -0.43 & -1.64 & -1.76 & -1.81 & -1.57 \\
\hline$\overline{\mathrm{SPI}}$ & 8 & -0.82 & -0.18 & -0.63 & -0.08 & -1.69 & -1.89 & -1.21 & -1.10 & -0.42 & -1.18 & -1.36 & -1.61 & -0.27 \\
\hline$\overline{\text { SPEI }}$ & 8 & -1.08 & -0.37 & -0.91 & -0.66 & -1.89 & -2.04 & -1.48 & -1.35 & -0.99 & -1.54 & -1.53 & -1.84 & -0.88 \\
\hline$\overline{\text { SPI }}$ & 12 & -0.59 & -0.22 & -0.08 & 0.38 & -0.39 & 0.20 & -0.57 & -0.33 & -0.12 & -0.42 & -0.65 & -0.36 & 0.80 \\
\hline$\overline{\text { SPEI }}$ & 12 & -0.79 & -0.24 & -0.21 & 0.09 & -0.55 & -0.35 & -1.02 & -1.00 & -0.28 & -0.97 & -0.96 & -0.93 & 0.30 \\
\hline SPI & 24 & 0.91 & 0.06 & 1.13 & 0.19 & 0.78 & 0.73 & 0.82 & 0.93 & 0.66 & 0.38 & -0.43 & 0.74 & 1.17 \\
\hline$\overline{\text { SPEI }}$ & 24 & 0.77 & 0.12 & 1.00 & 0.18 & 0.37 & 0.51 & 0.50 & 0.54 & 0.36 & 0.02 & -0.69 & 0.28 & 0.81 \\
\hline $\bar{Q}$ & & 0.19 & - & 0.23 & - & 0.12 & - & 0.13 & 0.19 & 0.09 & 0.09 & 0.02 & 0.13 & 0.15 \\
\hline $\bar{G}$ & & 0.33 & - & 0.39 & - & 0.34 & - & 0.39 & 0.49 & 0.42 & 0.42 & - & 0.24 & 0.40 \\
\hline
\end{tabular}

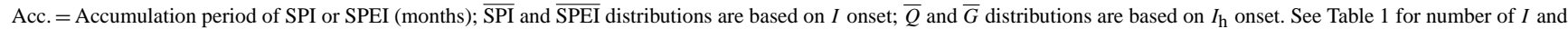
$I_{\mathrm{h}}$ per federal state; no data if number of $I$ or $I_{\mathrm{h}}$ onsets $<5$ or no indicator data available (BE/SL).

similarly negative as in the southern states. The findings above also apply to $\mathrm{SPI}_{10}$ and $\mathrm{SPEI}_{10}$, yet the threshold values are generally more negative (not shown).

2. Differences between SPI and SPEI and among accumulation periods - notable as well is that $\overline{\mathrm{SPEI}}$ or $\mathrm{SPEI}_{10}$ values triggering $I$ onset are in most cases more negative than the corresponding $\overline{\mathrm{SPI}}$ or $\mathrm{SPI}_{10}$ (see Fig. 4 and Table 3). Regarding timescales of SPI and SPEI, longer accumulation periods, especially 12 and 24 months, show less negative threshold values than shorter accumulation periods.

For streamflow and groundwater percentiles the onset of drought impacts is also concurrent with a range of threshold values (not shown). The median of thresholds lies between 0.02 and $0.23(\bar{Q})$ and 0.24 and $0.42(\bar{G})$ (see Table 3). Systematic differences among states are not discernible. However, for many states only very few $I_{\mathrm{h}}$ onsets exist, which does not allow for a robust characterization.

\subsection{Linkage between spatial patterns of indicator-impact data for selected drought events}

The maps in Fig. 5 reveal that there is a reasonable agreement between the spatial distribution of two exemplarily selected drought indicators $\left(\mathrm{SPEI}_{10}-3\right.$ and $\left.\bar{Q}\right)$ and number of $I$ or $I_{\mathrm{h}}$ per drought event. Nevertheless, there are differences among drought events. During all events except for 1971, the spatial patterns of $\mathrm{SPEI}_{10}-3$ versus $I$ match well apart from some exceptions. Opposed to that, the agreement between spatial patterns of indicator-impact data for the event in 1971 ( $I$ and $\left.I_{\mathrm{h}}\right)$, and in 1992 and $2006\left(I_{\mathrm{h}}\right)$ is lower. There, federal states affected by drought conditions show similar drought indicator values yet dissimilar $I$ and $I_{\mathrm{h}}$ patterns (e.g., 1971: SL and BV similar $\bar{Q}$ as NW, RP, and BW but no hydrological drought impact occurrence; 2006: hydrological drought in BB and MP according to $\bar{Q}$ yet no $I_{\mathrm{h}}$ ).

The correlation between spatial patterns of drought indicators and $I$ or $I_{\mathrm{h}}$ per event is displayed in Fig. 6. Rank correlation coefficients lie between -0.92 and 0.88 . When only considering the "best" indicator per drought event, i.e. the indicator with the highest absolute value of $r$, correlations range from 0.56 (1971) to 0.92 (2011). All strong correlations are statistically significant $(p<0.05)$, as indicated by the white dots in Fig. 6. Noticeable are a number of mostly non-significant correlations with non-meaningful direction of $r$, especially for the events 1971, and 2003 (positive $r$ for the metrics mean and 10th percentile; negative $r$ for percent area in drought). One commonality of all events is more pronounced differences between indicator metrics (mean versus 10th percentile versus percent area in drought) compared to the linkage-between-time-series approach (Sect. 3.1). For 


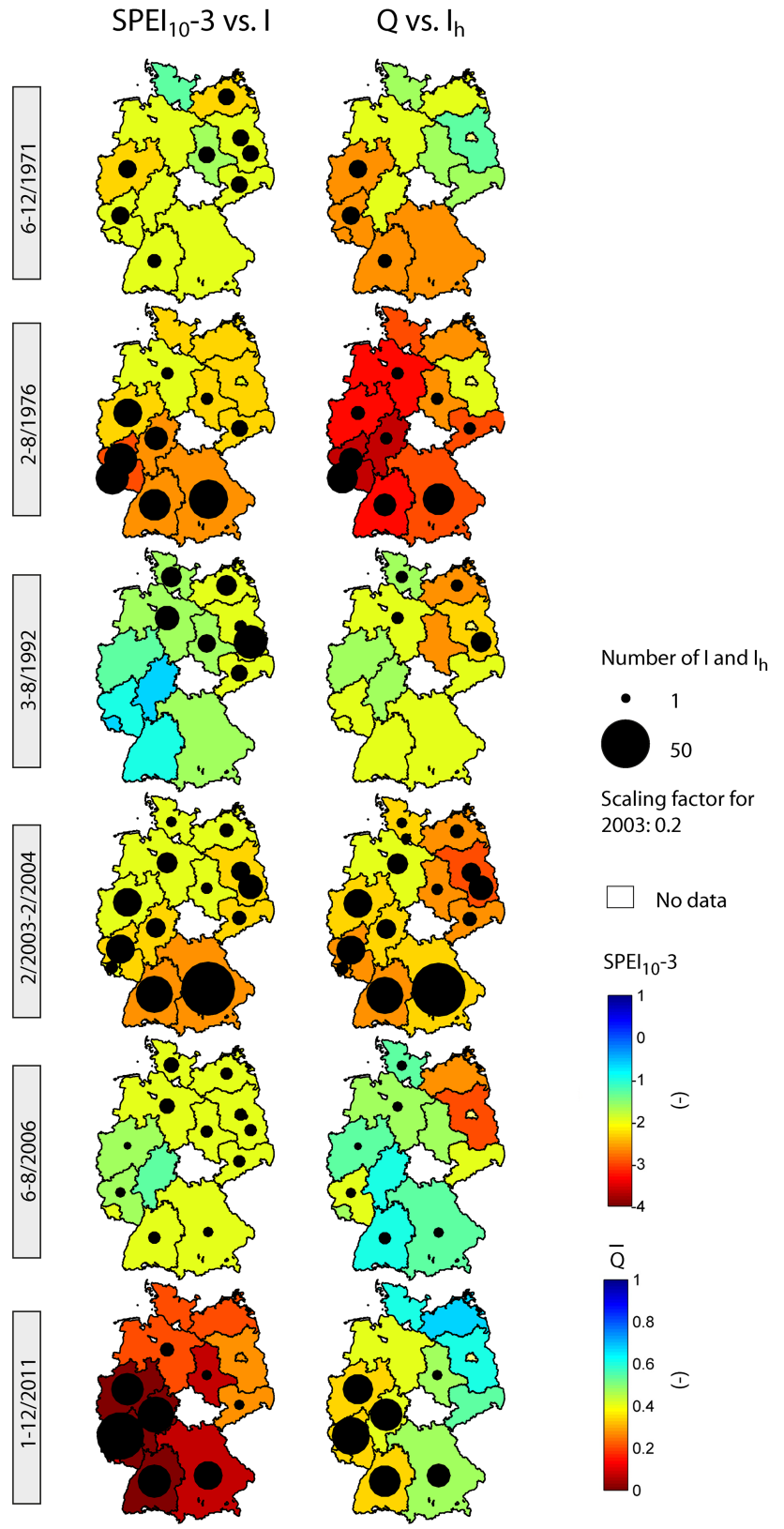

Figure 5. Thematic maps showing selected drought indicators ( SPEI $_{10}-3$ and $\bar{Q}$ ) versus number of drought impact occurrences $\left(I\right.$ and $\left.I_{\mathrm{h}}\right)$ per federal state and drought event.

some events the 10th percentile often performs slightly better than the mean (1971/2003/2006). Apart from this, Fig. 6 reveals clear differences among drought events. Drought events with geographical concentration (impact concentration in southern/southwestern states in 1976 and 2011, and in northeastern states in 1992) and thus larger spatial contrasts of indicator and/or impact data exhibit a higher number of indicators with a significant strong correlation (see Figs. 5 and 6). In contrast, the events of 2003 and 2006, where drought impacts occurred more evenly distributed in nearly all federal
Table 4. Median of indicator distribution ( $\overline{\mathrm{SPI}}$ or $\overline{\mathrm{SPEI}}$ or $\bar{Q}$ or $\bar{G})$ concurrent with drought impact onset per drought event. The bold values represent the indicator with highest $r$ between spatial patterns of drought indicators and $I$ per drought event.

\begin{tabular}{lcrrrrrr}
\hline & Acc. & 1971 & 1976 & 1992 & 2003 & 2006 & 2011 \\
\hline$\overline{\text { SPI }}$ & 1 & 1.37 & -1.70 & -1.04 & -1.07 & -1.05 & -2.22 \\
$\overline{\text { SPEI }}$ & 1 & 1.47 & -1.69 & -1.21 & $\mathbf{- 1 . 5 2}$ & -1.46 & -2.06 \\
$\overline{\text { SPI }}$ & 2 & $\mathbf{1 . 2 1}$ & -1.98 & -1.66 & -0.94 & -1.59 & $\mathbf{- 1 . 9 0}$ \\
$\overline{\text { SPEI }}$ & 2 & 1.24 & -1.73 & -1.59 & -1.35 & $-\mathbf{1 . 7 1}$ & -2.15 \\
$\overline{\text { SPI }}$ & 3 & 1.00 & -2.06 & -1.29 & -1.23 & -0.71 & -1.69 \\
$\overline{\text { SPEI }}$ & 3 & 0.95 & -2.10 & $-\mathbf{1 . 3 7}$ & -1.68 & -1.01 & -1.98 \\
$\overline{\text { SPI }}$ & 4 & 0.43 & -2.50 & -0.42 & -1.69 & -0.29 & -1.15 \\
$\overline{\text { SPEI }}$ & 4 & 0.43 & -2.10 & -0.91 & -1.78 & -0.81 & -1.45 \\
$\overline{\text { SPI }}$ & 5 & 0.28 & -2.86 & -0.45 & -1.93 & -0.02 & -0.84 \\
$\overline{\text { SPEI }}$ & 5 & 0.33 & -2.01 & -0.87 & -1.90 & -0.51 & -0.77 \\
$\overline{\text { SPI }}$ & 6 & -0.08 & -1.88 & -0.49 & -1.46 & -0.43 & -0.93 \\
$\overline{\text { SPEI }}$ & 6 & 0.00 & -1.91 & -0.90 & -1.84 & -0.62 & -0.96 \\
$\overline{\text { SPI }}$ & 7 & -0.26 & -2.02 & -0.42 & -1.49 & -0.57 & -1.00 \\
$\overline{\text { SPEI }}$ & 7 & -0.16 & $-\mathbf{2 . 0 1}$ & -0.78 & -1.74 & -0.64 & -1.17 \\
$\overline{\text { SPI }}$ & 8 & 0.01 & -2.32 & -0.37 & -1.18 & -0.80 & -1.16 \\
$\overline{\text { SPEI }}$ & 8 & 0.09 & -1.97 & -0.75 & -1.53 & -0.94 & -1.38 \\
$\overline{\text { SPI }}$ & 12 & -0.04 & -1.78 & -0.73 & 0.07 & -0.79 & -0.90 \\
$\overline{\text { SPEI }}$ & 12 & -0.02 & -1.72 & -1.17 & -0.35 & -1.00 & -1.21 \\
$\overline{\text { SPI }}$ & 24 & -0.40 & -0.66 & -1.02 & 0.87 & -0.59 & -0.62 \\
$\overline{\text { SPEI }}$ & 24 & -0.29 & -0.62 & -1.16 & 0.54 & -0.80 & -1.00 \\
$\bar{Q}$ & & 0.14 & 0.15 & 0.22 & 0.15 & 0.23 & 0.13 \\
$\bar{G}$ & & 0.35 & 0.20 & 0.20 & 0.40 & 0.33 & 0.36 \\
\hline
\end{tabular}

Acc $=$ Accumulation period of SPI or SPEI (months). $\overline{\text { SPI }}$ and $\overline{\text { SPEI distributions are based on }}$ $I$ onset, while $\bar{Q}$ and $\bar{G}$ distributions are based on $I_{\mathrm{h}}$ onset; no data if $I$ or $I_{\mathrm{h}}$ onset $<5$. For number of $I$ and $I_{\mathrm{h}}$ onsets per event see Table 2 .

states, show weaker and mostly non-significant correlations, many of them with a non-meaningful direction of $r$.

Regarding the "best" indicator there is a tendency of SPEI performing better than SPI, and SPEI or SPI outperforming streamflow and groundwater percentiles. Nevertheless, there is much variability among events, which also applies to the "best" SPI or SPEI timescale. Intermediate accumulation periods (roughly 3-8 months) correlate best with impact occurrence for the events of 1976 and 2006; shorter accumulation periods (2-4 months) yield the highest $r$ for 1992. For the 2011 event all accumulation periods show a moderate to high correlation with spatial patterns of impact data. The difference in $r$ between $I$ and $I_{\mathrm{h}}$ is rather low for the displayed events, except for 2006. While $I$ and $I_{\mathrm{h}}$ mostly differ in number of impact occurrences for the events 1976, 2003 and 2011 (decrease of $I_{\mathrm{h}}$ ), the spatial distribution of $I$ and $I_{\mathrm{h}}$ also changes for the 2006 event due to some states with no hydrological drought impacts (see maps in Fig. 5). A pattern of stronger correlation between streamflow/groundwater level percentiles and $I_{\mathrm{h}}$, however, does not exist; often correlations are lower.

Indicator thresholds associated with $I$ or $I_{\mathrm{h}}$ onset also reveal differences among events, highlighting the difficulty of identifying a single, time-invariant "best" threshold (see Fig. 7 and Table 4). For intermediate accumulation periods of 


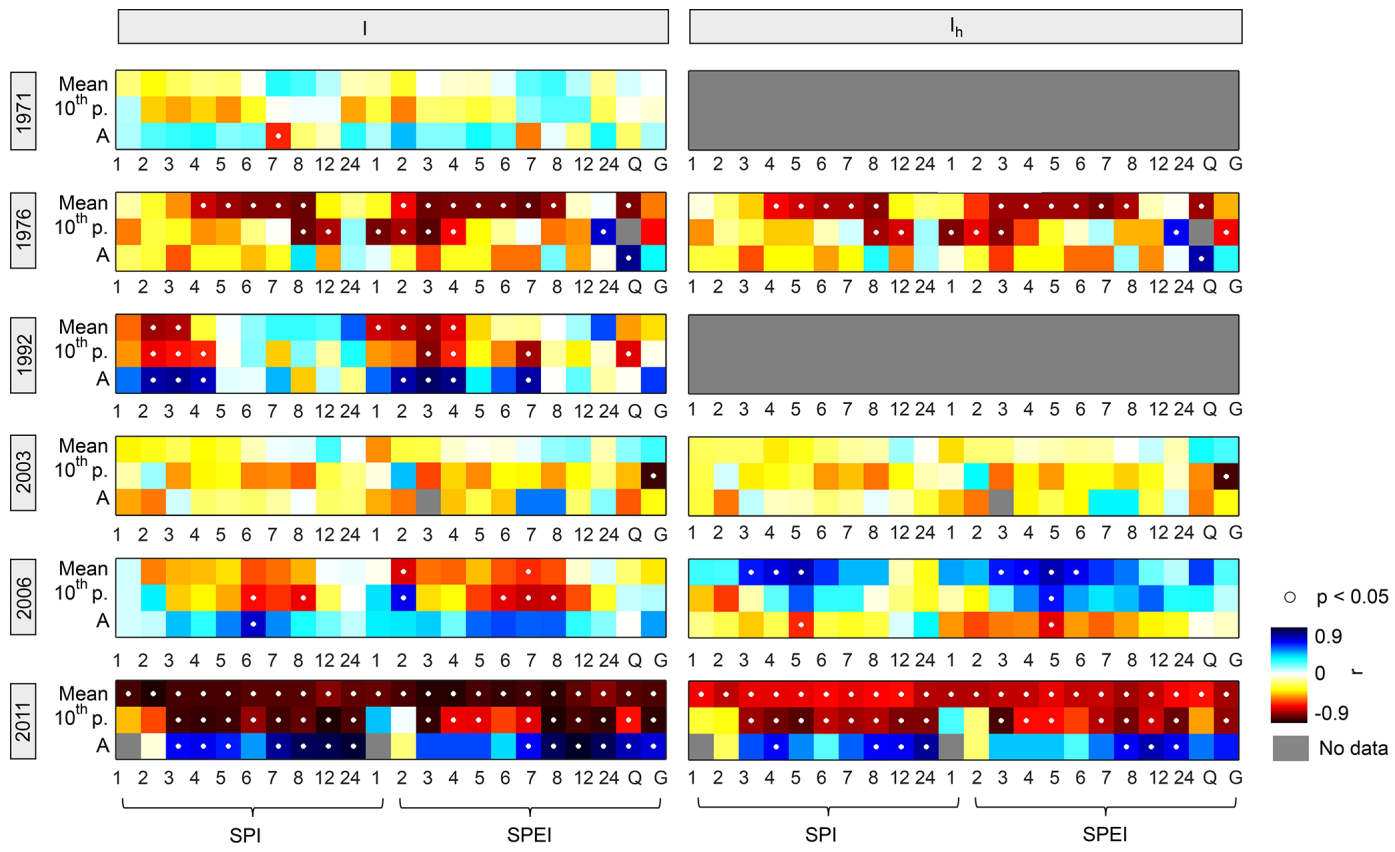

Figure 6. Rank correlation coefficients $(r)$ between spatial patterns of drought indicators (SPI or SPEI or streamflow $(Q)$ or groundwater level $(G)$ percentiles) and drought impact occurrences $\left(I\right.$ or $I_{\mathrm{h}}$ ) per drought event. Mean, 10th percentile, and $A$ (percent area in drought) represent different indicator metrics.
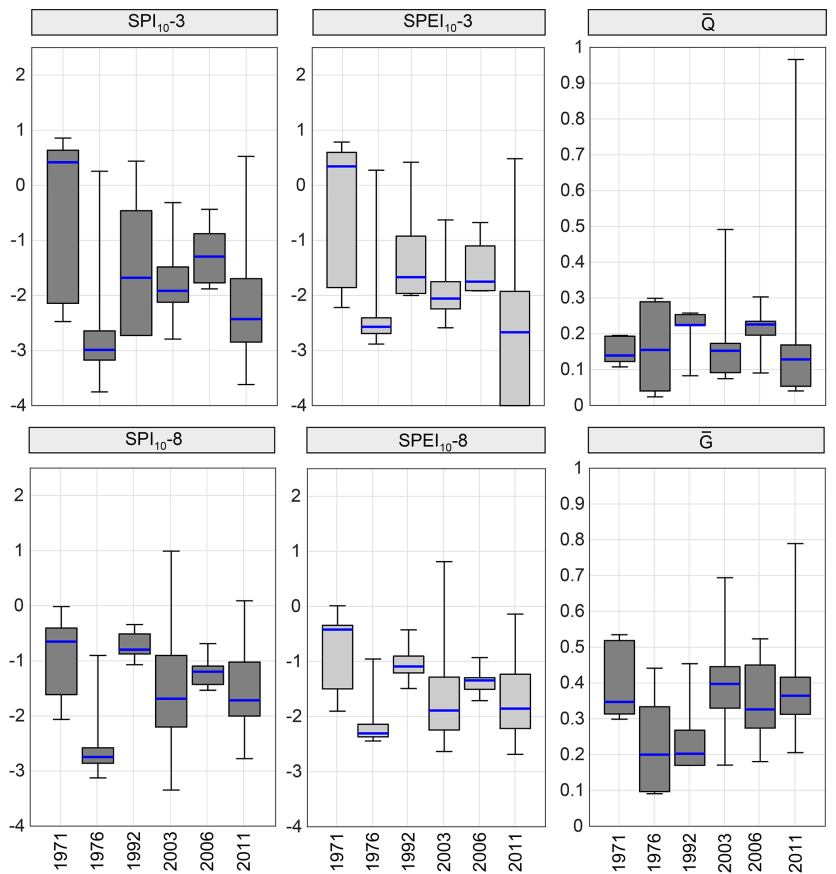

Figure 7. Distribution of selected drought indicators concurrent with $I$ onset $\left(\mathrm{SPI}_{10}\right.$ and $\left.\mathrm{SPEI}_{10}\right)$ or $I_{\mathrm{h}}$ onset $(\bar{Q}$ and $\bar{G})$ per drought event. The blue line inside each box plot represents the median; the whiskers of the box plots extend to the minimum and maximum of the distribution; for sample size of the box plots see Table 2 .
SPI or SPEI (3-8 months) the longer-duration events 1976, 2003, and 2011 show more negative threshold values than the other, shorter-duration events (median of SPI or SPEI distribution generally $<-1$ (Table 4); median of $\mathrm{SPI}_{10}$ or $\mathrm{SPEI}_{10}$ distribution generally $<-1.5$ (not shown)). For both short and long accumulation periods the differences in threshold values among events are less pronounced or disappear.

For streamflow percentiles similar differences among events are discernible, yet the differences are weaker. Groundwater level percentiles do not follow this pattern; thresholds were lowest in 1992 and 1976.

\section{Discussion}

\subsection{Is there a discernible link between drought impact occurrence derived from text-based information and different hydro-meteorologic indicators?}

The analysis clearly revealed a relationship between the selected hydro-meteorologic drought indicators and drought impact occurrence inferred from text-based reports. The linkage-between-time series approach (Sect. 3.1) showed a significant moderate strength of correlation for several federal states, allowing for intercomparing the performance of different drought indicators. The event-based approach (Sect. 3.2) also exposed a significant strong correlation between spatial patterns of indicator-impact data for some drought events and indicators. From these results one can in- 
fer that qualitative information on drought impacts has strong potential for evaluating the meaning of hydro-meteorologic drought indicators. This is highly relevant for improving drought M\&EW systems, since drought indicators are often used without having explicitly tested their representativeness for drought impact occurrence. Despite this promising outcome, it needs to be emphasized that for some federal states and drought events only a weak or no correlation was found, and sometimes a (mostly non-significant) correlation with non-meaningful direction.

For some states no to weak correlation may be an effect of very few months with impact occurrence $\mathrm{SH}, \mathrm{BE}$, and $\mathrm{SL}$ ), while this is not the case for the states MP, BB, and LS, which are comparable to SX, NW, and HE both regarding the number of impact occurrences and months with $I$ (see Table 1 and Fig. 2). While BV and BW have the highest number of $I$, which coincides with comparably strong correlations, they also show a similar number of months with $I$ as the above-named states. The underlying mechanisms of the differences between MP/BB/LS and SX/NW/HE despite a similar number of $I$ and months with $I$ are not clear; they may simply result from less representative impact data for MP/BB/LS. Lower variability of the impact and/or indicator time series may be another reason: the impact time series of these states show lower amplitude (smaller peak values), and the observed lower thresholds for impact onset in MP and LS indicate smaller differences in indicator values between months with and without impacts. In BV and BW comparably strong correlations concur with impact time series with larger amplitude.

Generally, there are many potential sources of error or bias concerning drought impact data. As described in Lackstrom et al. (2013), drought impact reporting is associated with numerous challenges, creating a "patchwork" of impact information. Concerning our analysis the following sources of uncertainty need to be pointed out: first, not all drought impacts become published in reports, newspaper articles or other sources; if they are published, the level of detail regarding the spatial and temporal reference likely differs. Second, not all published information will make it into the inventory if not easily found or accessible; when entering information about spatial and temporal reference and impact category further bias may be introduced. Third, the assumptions during the process of impact report quantification for this study are subjective. For instance, we simply sum up (hydrological) drought impact occurrences per month independent of impact severity or spatial extent of the impact. All drought impacts have equal weight. At the same time, we think that the amount of reported drought impacts may represent some measure of impact severity. Hence, the number of impact occurrences may provide more information than a binary target variable (impact versus no impact). Fourth, the small sample size for some of the federal states, and generally for the event-based analysis needs to be kept in mind as further error source.
Despite these limitations, the impact data used in this study provided a reasonable proxy for the linkage with hydrometeorologic indicators. Given the "patchwork" nature of impact information, uncertainty associated with the indicator data appears of lower importance (e.g., dissimilar amount of streamflow and groundwater gauging stations per state; small number of streamflow and groundwater gauging stations for MP, SH, and SL; choice of probability distribution for SPI or SPEI calculation (e.g., Stagge et al., 2015b); averaging SPI or SPEI data over regions differing in size. The reason for weak correlations for some drought events could also lie in the method of event delineation (e.g., impact occurrence in summer according to impact report, assignment of start month June during automatic data processing, yet start of meteorological/hydrological drought conditions in August). Another reason could be low spatial variability of impact and/or indicator data not allowing to detect a cause-effect relationship. Especially for the events 1971, 2003, and 2006, low spatial variability of impact and/or indicator data may explain the frequent occurrence of nonsignificant, weak correlations, often with non-meaningful direction of $r$. In 2003, drought conditions and heatwaves dominated entire central Europe (Fink et al., 2004). For relatively homogenous drought events like 2003 the linkage-betweenspatial-patterns approach does not yield useful insights into the indicator-impact relationship.

\subsection{Which indicator or set of indicators best explain drought impact occurrence for the case study area Germany?}

Generally speaking, the complementary approaches of linkage-between-time series and linkage-between-spatialpatterns of indicator-impact data revealed that (1) SPEI often correlates slightly better than SPI, (2) intermediate accumulation periods of SPI or SPEI show the highest correlation, (3) streamflow percentiles are comparable to SPI in many cases, and (4) the choice of indicator metric (mean versus minimum versus percent area in drought) does not make a difference for the between-time series approach, but matters for the event-based approach (10th percentile often outperforms mean/percent area in drought).

The finding that SPEI performed slightly better than SPI is in line with other studies assessing the correlation between SPI or SPEI and different hydrological, agricultural, and ecological response variables (Haslinger et al., 2014; Potop, 2011; Stagge et al., 2015a; Vicente-Serrano et al., 2012). The slightly better performance of SPEI highlights the importance of temperature and increased evapotranspiration in drought development in addition to a rainfall deficit (as for the 2003 event), as postulated by others (e.g., Trenberth et al., 2014; Vicente-Serrano et al., 2014). Also in terms of the "best" timescale of SPI or SPEI similar results were obtained as in other studies. Stagge et al. (2015a), who modeled drought impact occurrence for five European coun- 
tries based on logistic regression with different climatological drought indicators, identified an SPEI aggregation time of 3 months as best predictor for agricultural impact occurrence in Germany. For other impact categories in Germany, e.g., energy and industry, they obtained more complex results promoting a combination of shorter and longer accumulation periods (Stagge et al., 2015a). The observed shift towards stronger correlation with longer accumulation periods of SPI and SPEI for $I_{\mathrm{h}}$ over $I$ in our analysis concurs with this. $I_{\mathrm{h}}$ includes impacts from energy and industry (e.g., reduced production of thermal and nuclear power plants due to a lack of cooling water), and other impacts related to drought conditions in surface water and groundwater that take longer to establish.

Our finding that the "best" SPI or SPEI accumulation period differs among drought events could result from a shift in dominant impact type. For instance, the events in 1971, 1992, and 2006 show a higher fraction of agricultural impacts (see Fig. 2) as opposed to the other events with more diverse impact types, many of them evoked by low flows (e.g., impacts on waterborne transportation and energy production). Different impact types are known to have specific response times and could thus be attributed to different "best" SPI or SPEI timescales (e.g., shorter-term impacts on rain-fed agriculture versus longer-term impacts on water supply systems evoked by groundwater drought) (e.g., Stagge et al., 2015a; Vicente-Serrano et al., 2013). Overall, similar results as by Stagge et al. (2015a) are not surprising given that they also exploited EDII data to obtain binary impact information at the country level. However, it is important to test where simple and intuitive approaches like correlation and visualization of linkage patterns can yield similar results as more complex statistical models. The identified similar strength of correlation for streamflow as for SPI is noteworthy given the more complex streamflow signal stemming from several sources such as catchment area outside of the administrative area and human alteration through streamflow abstraction or augmentation. The weak correlation between groundwater levels and drought impact occurrence could be an effect of longer lag times of the groundwater response.

Apart from the above named commonalities, we observed differences in correlation patterns among federal states and drought events, highlighting the complexity of identifying a "best" indicator. It is known that an individual indicator is not capable of representing the diversity and complexity of drought conditions across space and time for different sectors (Botterill and Hayes, 2012; Hayes et al., 2005). Nevertheless, drought M\&EW systems rely on the use of meaningful indicators and associated triggers. Usually drought M \& EW systems operate on a national or continental scale and apply fixed rules for assigning drought intensity classes or issue warnings or alerts. One example is the European Drought Observatory (http://edo.jrc.ec.europa.eu), which assigns different alert levels inferred from a combination of drought indicators for entire Europe (European Drought Ob- servatory, 2013). Another example is the US Drought Monitor (http://droughtmonitor.unl.edu; USDM). The USDM produces nationwide weekly maps of drought severity categories based on a percentile approach of six key physical indicators and many supplementary indicators (Hayes et al., 2005; Svoboda et al., 2002). In addition, the USDM incorporates judgment from climate and water experts as a reality check at the state and local level, making it a "state-of-the-art blend of science and subjectivity" (http://droughtmonitor.unl.edu). Our analysis showed that a single "best" indicator for Germany could not be identified. Instead, the spatial variability in correlation patterns suggests that fixed rules representative for a larger area need to be selected with care. This is especially true since Germany is a comparably small country per se with lower spatial variability in climate and geographical properties as opposed to the whole of Europe or the US, for instance. Our study thus calls for evaluating the meaning of drought indictors at smaller spatial scales.

Furthermore, the linkage-between-spatial-patterns approach revealed clear differences among drought events. The drivers of the inter-event variability of correlation patterns and thus "best" indicators are less clear. Likely a combination of (1) dissimilar hazard characteristics (duration and evolution of drought severity and related hazards such as heat weaves) triggering different impact types, (2) differences in geographic extent and vulnerability of affected regions, (3) potentially an impact reporting bias for certain events and/or regions, and (4) changes in resilience over time due to adaptation to previous droughts cause the differences among events. On the one hand, experiencing drought and its impacts fosters drought planning and enhances preparedness (e.g., Wilhite and Buchanan-Smith, 2005), which likely alters the indicator-impact relationship over time. On the other hand, each drought differs due to unique hazard characteristics and societal feedbacks. Thus, new types of impacts likely occur during not yet experienced events that society is not prepared for to cope with, as suggested by Van Dijk et al. (2013) analyzing the natural and human causes of the Millennium Drought in Australia and its impacts.

Common to all events except 2011 is that they represent summer droughts with respect to peaks of drought impacts (see Table 2). Most drought impacts receded in the fall (1971, 1976, 1992, and 2006), while the 2003 drought was more persistent with longer-term drought impacts tapering off only in early 2004. From the hazard side, however, the droughts of 1976 and 1992 were more prolonged (e.g., Bradford, 2000; Hannaford et al., 2011; Zaidman et al., 2002). The 2011 drought was exceptional with regard to its unusual timing: after a flood in January two drought periods occurred in spring and late autumn, with November 2011 being the driest November recorded (Kohn et al., 2014). This may explain the comparably different correlation pattern for 2011, with SPI or SPEI from 1 to 8 months, streamflow and groundwater percentiles all performing similarly well showing strong correlation with impacts. While the reasons for the differences 
among events remain speculative, the inter-event variability suggests that the "best indicator" for drought impact occurrence is event-dependent. Nevertheless, the findings from the event-based analysis and the interpretations thereof need to be handled with care given the small sample size underlying the correlation between spatial patterns. Yet, we think the event-based analysis adds extra information on the variability over time complementing the insights from the linkagebetween-time series approach.

\subsection{Can impact occurrence be attributed to a specific indicator threshold?}

Regarding indicator thresholds triggering the onset of drought impacts we found that (1) no single "best" threshold value can be identified but impacts occur within a range of indicator values, (2) SPEI often shows slightly lower values than the corresponding SPI, and (3) there are differences among federal states and drought events.

Our analysis revealed that a single "one size fits all" indicator threshold does not exist. Instead, the interquartile range of the SPI or SPEI distributions was found to span an absolute value of roughly 0.3 to 1 in most federal states. The median of the threshold distribution, however, could be regarded as reference value for impact onset, e.g., to be used as trigger in drought management plans. Note that months with a high number of impact onsets, e.g., the summer months of 2003 in $\mathrm{BV}$, give strong weight to the threshold distribution. This explains the smaller IQR in BV. The spread of the indicator threshold distribution in most federal states is not surprising given the differences in impacts both regarding impact type and severity. We currently do not differentiate between impact types due to the small sample size; we only consider all drought impacts versus hydrological drought impacts. However, thresholds are likely specific to a certain impact category and affected sector, as already pointed out by Botterill and Hayes (2012). A split into more homogenous groups could lead to condensed threshold ranges, a prerequisite for inferring meaningful triggers. The Combined Drought Indicator by the European Drought Observatory, for instance, which is based on SPI-1, SPI-3, anomalies of soil moisture and FAPAR (Fraction of Absorbed Photosynthetically Active Radiation), builds on combinations of threshold values of -1 and -2 for assigning the agricultural drought levels "Watch", "Warning", and "Alert" (for details see corresponding product fact sheet; European Drought Observatory, 2013). The combined indicator geared towards agricultural drought detection was evaluated against data from the EM-DAT International Disaster Database and yield statistics, suggesting a robustness of the method against false alarms (SepulcreCanto et al., 2012). Information on impact onset derived from EDII reports could serve as valuable tool to derive meaningful warning thresholds for other types of drought.

A notable outcome of the analysis is differences in threshold values between southern/southwestern and most north- ern/northeastern states of Germany (SL, RP, BW, and BV versus SH, MP, LS, and ST). The differences mostly coincide with stronger and weaker correlation between indicatorimpact time series of the southern/southwestern and northern/northeastern states, respectively. Care needs to be taken regarding any interpretations given the "soft" text-based impact data and small sample size. However, one could speculate that these differences are attributable to differences in geographic properties, manifesting in different vulnerabilities to reduced precipitation input. The northern/northeastern states generally exhibit soils with higher sand content and thus lower water holding capacity than in the south (Bundesanstalt für Geowissenschaften und Rohstoffe, 2007). Additionally, there is lower natural water availability in the northern/northeastern federal states (Bundesamt für Gewässerkunde, 2003). This could serve as explanation for impact onset during less negative SPI or SPEI values than in the south. BB in the northeast of Germany showed similar SPI and SPEI thresholds (less negative) as the other northern states for short accumulation periods, yet not for longer ones. Other studies also report on lower soil moisture availability and higher drought vulnerability of the northeast of Germany (Samaniego et al., 2013; Schindler et al., 2007; Schröter et al., 2005). Regardless of the drivers of differences among states one could argue that assuming a fixed trigger applied to a large area varying in geographic properties may not be appropriate. For continental-scale drought M \& EW a systematic assessment of differences in threshold behavior could be useful.

In addition, the inter-event variability of thresholds associated with impact onset suggests that a "best" threshold is time variant. The analysis revealed comparably lower values associated with drought impact onset for the longer-duration, more severe events of 1976, 2003, and 2011. However, some events did not affect all states but were spatially concentrated (1992: focus on north-eastern Germany; 1976/2011: focus on the southwest). Differences in indicator thresholds among events could hence be a result of drought event characteristics, or an effect of location given the differences in threshold values between the south/north. For drought management plans aiming at withstanding a certain "design" drought, historical droughts of similar severity and duration could be jointly analyzed to derive reference thresholds triggering certain management actions during future events. While the visualization of indicator values corresponding to impact onset is a very simple approach, the suitability of threshold ranges can be easily judged. This was shown to be an important criterion for effective communication with stakeholders (Steinemann and Cavalcanti, 2006; Steinemann, 2014). 


\section{Conclusions}

We explored the link between hydro-meteorologic indicators and drought impacts for the case study area Germany to illustrate the potential of qualitative impact data for evaluating the meaning of drought indicators. The analysis clearly revealed a relationship between selected drought indicators (SPI, SPEI, streamflow and groundwater level percentiles) and drought impact occurrence inferred from text-based reports of the European Drought Impact report Inventory (EDII). Through data visualization, extraction of indicator values concurrent with impact onset, and correlation analysis several general conclusions concerning the performance of indicators, "best" indicator timescale, and thresholds associated with impact onset can be drawn. The notable differences in indicator-impact relationship among the federal states in Germany and among drought events, however, suggest that the linkage is time variant and region specific to some degree. We think that this study is a proof of concept and a first step in the direction of systematically characterizing the relationship between drought indicators and text-based impact reports. While the findings on "best" indicators and thresholds for impact onset strongly depend on data and may change with a growing number of impact reports in the future, the aim was to demonstrate the feasibility of evaluating hydro-meteorologic variables used for drought M \& EW with text-based impact reports. The complementary approaches of linkage between time series of indicatorimpact data per state and linkage between spatial patterns for selected drought events proved to be a simple, yet effective methodology for deriving strong hypotheses on general patterns of the indicator-impact relationship. Consequently, this study highlights the value of impact reporting as a tool for monitoring drought conditions and stresses the necessity to further develop drought impact inventories.

Acknowledgements. Funding to the project DrIVER by the German Research Foundation DFG under the international Belmont Forum/G8HORC's Freshwater Security programme (project no. STA-632/2-1) and to the EU-FP7 DROUGHT R \& SPI project (contract no. 282769) is gratefully acknowledged. We thank Lukas Gudmundsson for the provision of SPI and SPEI gridded data developed within the DROUGHT R\&SPI project. We further thank the following agencies of the German federal states for supplying streamflow and groundwater level data through the Bundesanstalt für Gewässerkunde-funded project "Extremjahr 2011": Bayerisches Landesamt für Umwelt (LfU), Hessisches Landesamt für Umwelt und Geologie (HLUG), Landesamt für Natur, Umwelt und Verbraucherschutz Nordrhein-Westfalen (LANUV), Landesamt für Umwelt und Arbeitsschutz Saarland (LUA), Landesamt für Umwelt, Naturschutz und Geologie Mecklenburg-Vorpommern (LUNG), Landesamt für Umwelt, Wasserwirtschaft und Gewerbeaufsicht Rheinland-Pfalz (LUWG), Landesanstalt für Umwelt, Gesundheit und Verbraucherschutz Brandenburg (LUGV, Regionalabteilungen Ost, Süd, West), Landesanstalt für Umwelt, Messungen und Naturschutz Baden-
Württemberg (LUBW), Landesbetrieb für Hochwasserschutz und Wasserwirtschaft Sachsen-Anhalt (LHW), Landesbetrieb für Küstenschutz, Nationalpark und Meeresschutz Schleswig-Holstein (LKNM), Niedersächsischer Landesbetrieb für Wasserwirtschaft, Küsten- und Naturschutz (NLWKN), Ruhrverband, Sächsisches Landesamt für Umwelt, Landwirtschaft und Geologie (LfULG), Staatliches Amt für Landwirtschaft und Umwelt Vorpommern (StALU-VP), Thüringer Landesamt für Umwelt und Geologie (TLUG), Landesamt für Landwirtschaft, Umwelt und ländliche Räume (LLUR), and Wasser- und Schifffahrtsverwaltung des Bundes (WSV). Last, we thank A. van Dijk, C. Svensson, and an anonymous referee for providing valuable suggestions for improving the manuscript.

Edited by: P. Tarolli

Reviewed by: A. van Dijk and another anonymous referee

\section{References}

Anderson, M. C., Hain, C., Wardlow, B., Pimstein, A., Mecikalski, J. R., and Kustas, W. P.: Evaluation of Drought Indices Based on Thermal Remote Sensing of Evapotranspiration over the Continental United States, J. Climate, 24, 2025-2044, doi:10.1175/2010JCLI3812.1, 2011.

Birkmann, J., Cardona, O. D., Carreño, M. L., Barbat, A. H., Pelling, M., Schneiderbauer, S., Kienberger, S., Keiler, M., Alexander, D., Zeil, P. and Welle, T.: Framing vulnerability, risk and societal responses: the MOVE framework, Nat. Hazards, 67, 193-211, doi:10.1007/s11069-013-0558-5, 2013.

Blauhut, V., Gudmundsson, L., and Stahl, K.: Towards panEuropean drought risk maps: quantifying the link between drought indices and reported drought impacts, Environ. Res. Lett., 10, 014008, doi:10.1088/1748-9326/10/1/014008, 2015.

Botterill, L. C. and Hayes, M. J.: Drought triggers and declarations: science and policy considerations for drought risk management, Nat. Hazards, 64, 139-151, doi:10.1007/s11069-0120231-4, 2012.

Bradford, R. B.: Drought Events in Europe, in: Drought and Drought Mitigation in Europe, vol. 14, edited by: Vogt, J. V. and Somma, F., Springer Netherlands, Dordrecht, 7-20, 2000.

Bundesamt für Gewässerkunde: Hydrologischer Atlas von Deutschland, Bundesministerium für Umwelt, Naturschutz und Reaktorsicherheit, Berlin, 2003.

Bundesanstalt für Geowissenschaften und Rohstoffe: Bodenarten in Oberböden Deutschlands 1: 1000 000, Hannover, 2007.

Ceglar, A., Medved-Cvikl, B., Moran-Tejeda, E., Vicente-Serrano, S. M., and Kajfež-Bogataj, L.: Assessment of multi-scale drought datasets to quantify drought severity and impacts in agriculture: a case study for Slovenia, Int. J. Spat. Data Infrastruct. Res., 7, 464-487, doi:10.2902/1725-0463.2012.07.art21, 2012.

Dieker, E., van Lanen, H. A. J., and Svoboda, M.: Comparison of three drought monitoring tools in the USA. WATCH Technical Report No. 25, available at: http://www.eu-watch. org/publications/technical-reports/3 (last access: 11 December 2014), 2010.

European Drought Observatory: PRODUCT FACT SHEET: Combined Drought Indicator - EUROPE, available at: http://edo.jrc. 
ec.europa.eu/edov2/php/index.php?id=1101 (last access: 11 December 2014), 2013.

Fink, A. H., Brücher, T., Krüger, A., Leckebusch, G. C., Pinto, J. G., and Ulbrich, U.: The 2003 European summer heatwaves and drought-synoptic diagnosis and impacts, Weather, 59, 209-216, 2004.

Gillette, H.: A creeping drought under way, Water Sewage Works, 97, 104-105, 1950.

Gudmundsson, L., Rego, F. C., Rocha, M., and Seneviratne, S. I.: Predicting above normal wildfire activity in southern Europe as a function of meteorological drought, Environ. Res. Lett., 9, 084008, doi:10.1088/1748-9326/9/8/084008, 2014.

Hannaford, J., Lloyd-Hughes, B., Keef, C., Parry, S., and Prudhomme, C.: Examining the large-scale spatial coherence of European drought using regional indicators of precipitation and streamflow deficit, Hydrol. Process., 25, 1146-1162, doi:10.1002/hyp.7725, 2011.

Hao, Z. and AghaKouchak, A.: A Nonparametric Multivariate Multi-Index Drought Monitoring Framework, J. Hydrometeorol., 15, 89-101, doi:10.1175/JHM-D-12-0160.1, 2014.

Hargreaves, G. H.: Defining and Using Reference Evapotranspiration, J. Irrig. Drain. Eng., 120, 1132-1139, doi:10.1061/(ASCE)0733-9437(1994)120:6(1132), 1994.

Haslinger, K., Koffler, D., Schöner, W., and Laaha, G.: Exploring the link between meteorological drought and streamflow: Effects of climate-catchment interaction, Water Resour. Res., 50, 24682487, doi:10.1002/2013WR015051, 2014.

Hayes, M. J., Svoboda, M., Le Comte, D., Redmond, K. T., and Pasteris, P.: Drought Monitoring: New Tools for the 21st Century, in: Drought and water crisis: science, technology, and management issues, edited by: Wilhite, D. A., CRC Press, Taylor \& Francis Group, 54-69, 2005.

Haylock, M. R., Hofstra, N., Klein Tank, A. M. G., Klok, E. J., Jones, P. D., and New, M.: A European daily highresolution gridded data set of surface temperature and precipitation for 1950-2006, J. Geophys. Res., 113, D20119, doi:10.1029/2008JD010201, 2008.

Heim Jr., R. R.: A review of twentieth-century drought indices used in the United States, B. Am. Meteorol. Soc., 83, 1149-1165, 2002.

Hurlbert, S. H.: Pseudoreplication and the Design of Ecological Field Experiments, Ecol. Monogr., 54, 187, doi:10.2307/1942661, 1984.

Jenkins, G.: The influence of climate on the fishery recruitment of a temperate, seagrass-associated fish, the King George whiting Sillaginodes punctata, Mar. Ecol.-Prog. Ser., 288, 263-271, 2005.

Kallis, G.: Droughts, Annu. Rev. Environ. Resour., 33, 85-118, doi:10.1146/annurev.environ.33.081307.123117, 2008.

Keyantash, J. and Dracup, J. A.: The Quantification of Drought: An Evaluation of Drought Indices, B. Am. Meteorol. Soc., 83, 1167-1180, 2002.

Knutson, C. L., Hayes, M. J., and Philipps, T.: How to Reduce Drought Risk, Western Drought Coordination Council Preparedness and Mitigation Working Group, Lincoln, 1998.

Kohn, I., Rosin, K., Freudiger, D., Belz, J. U., Stahl, K., and Weiler, M.: Niedrigwasser in Deutschland 2011, Hydrol. Wasserbewirt., 58, 4-17, doi:10.5675/HyWa_2014,1_1, 2014.
Krzywinski, M. and Altman, N.: Points of Significance: Visualizing samples with box plots, Nat. Methods, 11, 119-120, doi:10.1038/nmeth.2813, 2014.

Lackstrom, K., Brennan, A., Ferguson, D., Crimmins, M., Darby, L., Dow, K., Ingram, K., Meadow, A., Reges, H., Shafer, M., and Smith, K.: The Missing Piece: Drought Impacts Monitoring. Workshop report produced by the Carolinas Integrated Sciences \& Assessments program and the Climate Assessment for the Southwest, 5-6 March 2013, Tucson, AZ, 1-23, 2013.

Logar, I. and van den Bergh, J. C. J. M.: Methods to Assess Costs of Drought Damages and Policies for Drought Mitigation and Adaptation: Review and Recommendations, Water Resour. Manage., 27, 1707-1720, doi:10.1007/s11269-012-0119-9, 2013.

Mavromatis, T.: Drought index evaluation for assessing future wheat production in Greece, Int. J. Climatol., 27, 911-924, 2007.

McKee, T. B., Doesken, N. J., and Kleist, J.: The Relationship of Drought Frequency and Duration to Time Scales, Preprints, 8th Conference on Applied Climatology, 17-22 January 1993, Anaheim, California, 179-184, 1993.

Naumann, G., Barbosa, P., Garrote, L., Iglesias, A., and Vogt, J.: Exploring drought vulnerability in Africa: an indicator based analysis to be used in early warning systems, Hydrol. Earth Syst. Sci., 18, 1591-1604, doi:10.5194/hess-18-1591-2014, 2014.

Potop, V.: Evolution of drought severity and its impact on corn in the Republic of Moldova, Theor. Appl. Climatol., 105, 469-483, doi:10.1007/s00704-011-0403-2, 2011.

Pyper, B. J. and Peterman, R. M.: Comparison of methods to account for autocorrelation in correlation analyses of fish data, Can. J. Fish. Aquat. Sci., 55, 2127-2140, 1998.

Quiring, S. M. and Ganesh, S.: Evaluating the utility of the Vegetation Condition Index (VCI) for monitoring meteorological drought in Texas, Agr. Forest Meteorol., 150, 330-339, 2010.

Quiring, S. M. and Papakryiakou, T. N.: An evaluation of agricultural drought indices for the Canadian prairies, Agr. Forest Meteorol., 118, 49-62, 2003.

Rossi, S. and Niemeyer, S.: Monitoring droughts and impacts on the agricultural production: examples from Spain, in: Economics of Drought and Drought Preparedness in a Climate Change Context, edited by: López-Francos, A., CIHEAM/FAO/ICARDA/GDAR/CEIGRAM/MARM, Zaragoza, 35-40, 2010.

Samaniego, L., Kumar, R., and Zink, M.: Implications of parameter uncertainty on soil moisture drought analysis in Germany, J. Hydrometeorol., 14, 47-68, doi:10.1175/JHM-D-12-075.1, 2013.

Schindler, U., Steidl, J., Müller, L., Eulenstein, F., and Thiere, J.: Drought risk to agricultural land in Northeast and Central Germany, J. Plant Nutr. Soil Sci., 170, 357-362, doi:10.1002/jpln.200622045, 2007.

Schröter, D., Zebisch, M., and Grothmann, T.: Climate change in Germany-vulnerability and adaptation of climate-sensitive sectors, Klimastatusbericht des DWD, available at: https://www. pik-potsdam.de/news/public-events/archiv/alter-net/former-ss/ 2008/working-groups/literature/schroeter-et-al-ksb06.pdf (last access: 11 September 2014), 2005.

Sepulcre-Canto, G., Horion, S., Singleton, A., Carrao, H., and Vogt, J.: Development of a Combined Drought Indicator to detect agricultural drought in Europe, Nat. Hazards Earth Syst. Sci., 12, 3519-3531, doi:10.5194/nhess-12-3519-2012, 2012. 
Stagge, J. H., Kohn, I., Tallaksen, L. M., and Stahl, K.: Modeling drought impact occurrence based on climatological drought indices for Europe, J. Hydrol., in review, 2015a.

Stagge, J. H., Tallaksen, L. M., Gudmundsson, L., Van Loon, A. F., and Stahl, K.: Candidate Distributions for Climatological Drought Indices (SPI and SPEI), Int. J. Climatol., doi:10.1002/joc.4267, in press, 2015b.

Stahl, K., Blauhut, V., Kohn, I., Acácio, V., Assimacopoulos, D., Bifulco, C., De Stefano, L., Dias, S., Eilertz, D., Frielingsdorf, B., Hegdahl, T., Kampragou, E., Kourentzis, V., Melsen, L., Van Lanen, H., Van Loon, A., Massarutto, A., Musolino, D., De Paoli, L., Senn, L., Stagge, J., Tallaksen, L., and Urquijo, J.: A European Drought Impact Report Inventory (EDII): Design and Test for Selected Recent Droughts in Europe, DROUGHT-R \& SPI Technical Report No. 3, available at: http://www.eu-drought.org/ technicalreports/3 (last access: 11 December 2014), 2012.

Stahl, K., Kohn, I., De Stefano, L., Tallaksen, L. M., Rego, F. C., Seneviratne, S. I., Andreu, J., and Van Lanen, H. A. J.: An impact perspective on pan-European drought sensitivity, in: Drought: Research and Science-Policy Interfacing, edited by: Alvarez, J. A., Solera, A., Paredes-Arquiola, J., HaroMonteagudo, D., and van Lanen, H., CRC Press, London, 329334, doi:10.1201/b18077-56, 2015.

Steinemann, A.: Drought Indicators and Triggers: A Stochastic Approach to Evaluation, J. Am. Water Resour. Assoc., 93, 12171233, 2003.

Steinemann, A.: Drought Information for Improving Preparedness in the Western States, B. Am. Meteorol. Soc., 95, 843-847, doi:10.1175/bams-d-13-00067.1, 2014.

Steinemann, A. C. and Cavalcanti, L. F. N.: Developing multiple indicators and triggers for drought plans, J. Water Resour. Pl. Manage., 132, 164-174, 2006.

Svoboda, M., LeComte, D., Hayes, M., Heim, R., Gleason, K., Angel, J., Rippey, B., Tinker, R., Palecki, M., and Stooksbury, D.: The drought monitor, B. Am. Meteorol. Soc., 83, 1181-1190, 2002.

Trenberth, K. E., Dai, A., van der Schrier, G., Jones, P. D., Barichivich, J., Briffa, K. R., and Sheffield, J.: Global warming and changes in drought, Nat. Clim. Change, 4, 17-22, 2014.

UN General Secretariat: United Nations Convention to Combat Drought and Desertification in Countries Experiencing Serious Droughts and/or Desertification, Particularly in Africa, Paris, 1994.

Van Dijk, A. I. J. M., Beck, H. E., Crosbie, R. S., de Jeu, R. A. M., Liu, Y. Y., Podger, G. M., Timbal, B., and Viney, N. R.: The Millennium Drought in southeast Australia (2001-2009): Natural and human causes and implications for water resources, ecosystems, economy, and society, Water Resour. Res., 49, 1040-1057, doi:10.1002/wrcr.20123, 2013.
Vicente-Serrano, S. M., Beguería, S., and López-Moreno, J. I.: A multiscalar drought index sensitive to global warming: the standardized precipitation evapotranspiration index, J. Climate, 23, 1696-1718, 2010.

Vicente-Serrano, S. M., Beguería, S., Lorenzo-Lacruz, J., Camarero, J. J., López-Moreno, J. I., Azorin-Molina, C., Revuelto, J., Morán-Tejeda, E., and Sanchez-Lorenzo, A.: Performance of drought indices for ecological, agricultural, and hydrological applications, Earth Interact., 16, 1-27, 2012.

Vicente-Serrano, S. M., Gouveia, C., Camarero, J. J., Beguería, S., Trigo, R., López-Moreno, J. I., Azorín-Molina, C., Pasho, E., Lorenzo-Lacruz, J., Revuelto, J., Morán-Tejeda, E., and SanchezLorenzo, A.: Response of vegetation to drought time-scales across global land biomes, P. Natl. Acad. Sci. USA, 110, 52-7, doi:10.1073/pnas.1207068110, 2013.

Vicente-Serrano, S. M., Van der Schrier, G., Beguería, S., Azorin-Molina, C., and Lopez-Moreno, J.-I.: Contribution of precipitation and reference evapotranspiration to drought indices under different climates, J. Hydrol., 526, 42-54, doi:10.1016/j.jhydrol.2014.11.025, 2014.

Wilhite, D. A. and Buchanan-Smith, M.: Drought as a Hazard: Understanding the Natural and Social Context, in: Drought and water crisis?: science, technology, and management issues, edited by: Wilhite, D. A., CRC Press, Taylor \& Francis Group, 3-29, 2005.

Wilhite, D. A. and Knutson, C.: Drought management planning: conditions for success, Options Mediterr. Ser. A, 80, 141-148, 2008.

Wilhite, D. A. and Svoboda, M.: Drought early warning systems in the context of drought preparedness and mitigation, in: EarlyWarning Systems for Drought Preparedness and Drought Management, edited by: Wilhite, D. A., Sivakumar, M. V. K., and Wood, D. A., Proceedings of an Expert Group Meeting held in Lisbon, Portugal, 5-7 September 2000, World Meteorological Organization, Geneva, Switzerland, 1-21, 2000.

Wilhite, D. A., Hayes, M. J., Knutson, C., and Smith, K. H.: Planning for drought: Moving from crisis to risk management, J. Am. Water Resour. Assoc., 36, 697-710, 2000.

Wilhite, D. A., Svoboda, M. D., and Hayes, M. J.: Understanding the complex impacts of drought: A key to enhancing drought mitigation and preparedness, Water Resour. Manage., 21, 763-774, doi:10.1007/s11269-006-9076-5, 2007.

Zaidman, M. D., Rees, H. G., and Young, A. R.: Spatio-temporal development of streamflow droughts in north-west Europe, Hydrol. Earth Syst. Sci., 6, 733-751, doi:10.5194/hess-6-733-2002, 2002.

Zargar, A., Sadiq, R., Naser, B., and Khan, F. I.: A review of drought indices, Environ. Rev., 19, 333-349, 2011. 